\title{
Reducing prejudice in the society at large: A review of the secondary transfer effect and directions for future research
}

\author{
Loris Vezzali ${ }^{1}$ (1) | Gian Antonio Di Bernardo ${ }^{1}$ \\ Veronica Margherita $\operatorname{Cocco}^{2}$ (1) | Sofia Stathi ${ }^{3}$ \\ Dora Capozza4
}

\section{1 | INTRODUCTION}

Ample empirical evidence has shown that intergroup contact is an effective strategy for prejudice reduction (Hodson \& Hewstone, 2013; Pettigrew \& Tropp, 2006). In order to test whether the effects of contact are confined to the specific situation where it occurred and only refer to attitudes toward the immediate target, or instead extend beyond it, scholars have examined different types of attitude generalizations. Research has mostly focused on generalization from the outgroup member(s) one has contact with to the larger outgroup category. There is now consistent evidence supporting this type of generalization (Pettigrew \& Tropp, 2006). But there is also a further type of generalization, which, according to Pettigrew (1998), is likely the most difficult to achieve. It refers to the generalization from the outgroup one has contact with to outgroups uninvolved in the contact situation. Pettigrew (2009) referred to this as "secondary transfer effect" (STE). In particular, the STE occurs when contact with an outgroup ("primary outgroup") impacts on attitudes toward another outgroup that was not involved in the initial contact situation ("secondary outgroup"). For example, individuals may show improved attitudes toward gay people (secondary outgroup) as a function of positive contact with immigrants (primary outgroup). This potential of contact effects to generalize beyond the primary outgroup to secondary outgroups is critical given that people cannot realistically have contact with individuals belonging to all the different groups within a given society. If contact effects do not generalize to uninvolved outgroups, although important for the immediate context, they have limited relevance when considering broader societal concerns.

In this article, we provide a review of the empirical research on the STE. Lolliot et al. (2013) previously reviewed the STE literature, attesting the existence and robustness of the phenomenon, and identifying key mediating processes and moderating variables. We believe that in the 8 years following Lolliot et al.'s review, research on the STE has notably expanded, both quantitatively (e.g., in terms of mediators uncovered) and qualitatively (e.g., allowing to differentiate three distinct categories of mediators and testing new contact forms). We thus argue that it is critical to review the existing literature in light of new developments. We will return to these points in more detail in the Discussion. The present review is also different from Boin et al.'s (2021) contribution. In their review, Boin et al. provide a brief overview of the STE, as well as of the other generalizations stemming from contact, while concentrating on the implications of such contact generalizations for social policy and interventions.

Surprisingly, scholars exploring the STE have not engaged in a more general conceptualization of what prejudice toward secondary outgroups means. To us, and pertinent to this review, such conceptualization aligns with the concept of ethnocentrism, specifically with generalized prejudice (Akrami, Ekehammar, \& Bergh, 2011; LeVine \& Campbell, 1972; Sumner, 1906). We believe that generalized prejudice and the STE are critically intertwined.

Akrami et al. (2011) differentiated between the common and the specific component of prejudice. While the specific component taps on variance referred to a specific group, the common component refers to variance of prejudice shared by all groups. The common component represents what we refer to as generalized prejudice. As an example, let us consider attitudes toward immigrants, gay people, and people with disability; such attitudes will partly reflect variance specific to each group and not shared with the other two groups (specific component). However, they will also have shared variance that is common among the three groups (common component). Akrami et al. (2011) provided empirical evidence for such a 
distinction, further finding that the common component of prejudice is largely a function of personality (see also, Bergh, Akrami, Sidanius, \& Sibley, 2016; Levin et al., 2016; Meeusen, Barlow, \& Sibley, 2017).

A further concept related to the potential for generalization of contact effects has been proposed by Hodson, Crisp, Meleady, and Earle (2018), according to whom intergroup contact is an agent of cognitive liberalization. The effects of contact may in fact extend beyond improving outgroup attitudes; contact can provide a new lens to interpret and handle reality; it

can challenge one's worldview and favor cognitive growth, empowering individuals also by fostering greater cognitive flexibility and problem-solving skills. This type of generalization has been labelled "tertiary transfer effect" (Meleady, Crisp, Hodson, \& Earle, 2019; see also; Boin et al., 2021).

The main aim of our review is to examine current research on the STE, by providing tools to further understand the potential of contact for generalization beyond the initial premises of the STE (i.e., attitude generalization), highlighting the links with generalized prejudice and cognitive liberalization. After providing evidence for the STE, we will discuss methodological issues associated with it. Moving to the main focus of this review, we will consider the underlying mechanisms of the STE, by differentiating them into three categories of mediators, involving the outgroup, the ingroup, and the self, before presenting moderators of the STE. To the extent that contact can change how the person conceptualizes the ingroup, which is inextricably associated with intergroup distinctions, or the very nature of the self in terms of ideological orientations or personality, contact may have an impact that goes beyond specific outgroups. Therefore, a distinction of the processes underlying different types of generalization, as presented here, is meant to stimulate future research; see section "Future research").

Although research has mainly considered the STE of direct contact, there is some evidence that the STE can occur via indirect forms of contact. We will review this literature, before outlining emerging research on the STE of negative contact. We will finally conclude by presenting directions for future research. In so doing, we will present a theoretical model of the STE. The reviewed studies are presented in Table 1 (experimental studies), Table 2 (longitudinal studies), and Table 3 (correlational studies). In the tables, we have provided information that may help the reader navigate the STE literature. First, we included information on participants and where the studies were conducted. Second, we specified the primary and secondary outgroups under consideration (which helps, for instance, understand whether the STE concerned stigmatized groups, or whether transfer between similar and/or dissimilar outgroup was tested). Third, we included the type of contact considered in the studies (direct contact, or some forms of indirect contact), while specifying whether it was positive or negative. Fourth, we added two columns in the tables noting the mediators and moderators tested in each study (by also categorizing mediators in terms of the distinction we suggest in this review, see section on "Mediators of the secondary transfer effect"). This way, there are clear indications regarding where existing research has concentrated on and where future research may be directed. An additional column indicates the dependent variable(s), showing the heterogeneity of the tests that have often gone beyond the mere examination of outgroup attitudes. Finally, we included two columns with the methodological controls that researchers have used, which is important when interpreting findings (see section on "Methodological issues").

The theoretical model is presented in Figure 1. In the model, we differentiate between direct and indirect contact (without differentiating between indirect contact forms, as research on them is still at an early stage; see section on "Indirect intergroup contact"). Mediators are included in the figure according to the distinction we propose (see section on "Mediators of the secondary transfer effect"). We also include moderators, indicating the paths they are expected to moderate (from independent variables to mediators or from mediators to dependent variables). Note that although the model is largely based on existing research, it also includes our suggestions where research is missing (e.g., the mediators that should be affected by indirect contact or some mediators that still remain to be tested, for instance personality).

\section{INTERGROUP CONTACT AND THE SECONDARY TRANSFER EFFECT}

According to the contact hypothesis (Allport, 1954), positive interactions between members of different groups can reduce prejudice when contact is characterized by optimal conditions, that is, equal status, cooperation for common goals, and 
institutional support (Allport, 1954). Decades of research revealed the effectiveness of contact for the improvement of intergroup relations, even in the absence of the optimal contact conditions (Pettigrew \& Tropp, 2006). Also, in contrast to Allport's (1954) initial concerns, intergroup contact was shown to be effective (and in some cases, its effects are even stronger) among individuals more intolerant of the outgroup (Turner, Hodson, \& Dhont, 2020). Research has also demonstrated that the effects of contact generalize from known outgroup members to the outgroup as a whole, especially when group membership is salient during contact (Brown \& Hewstone, 2005). However, this generalization effect is more likely to emerge among admired outgroups, while negative experiences (e.g., negative contact) may have a generalization advantage in the case of stigmatized outgroups (Paolini \& Mclntyre, 2019). 


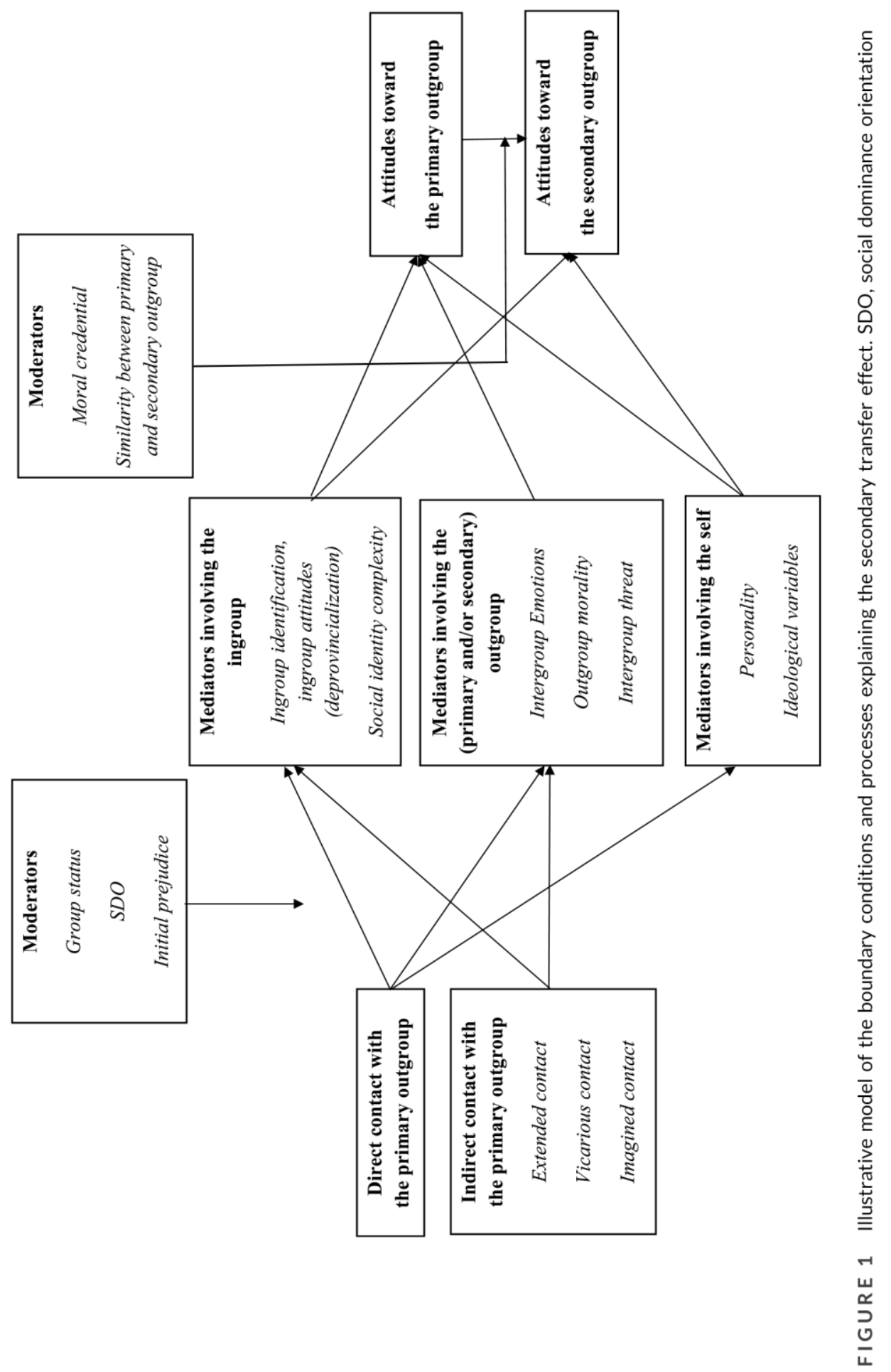

Evidence for the occurrence of the STE started accumulating in the 1970s. Weigert (1976) conducted a correlational study with Black soldiers and found that positive contact with White soldiers stationed in West Germany was associated with more positive attitudes toward West German civilians. Clement, Gardner, and Smythe (1977) found evidence in a further correlational study that contact with French Canadians was associated with Canadian Anglophones' attitudes toward French people in general. Further evidence was provided approximately two decades later by Pettigrew (), who surveyed crosssectionally approximately 3,806 participants from seven national probability samples in France, the United Kingdom, West Germany, and the Netherlands. The results showed an association between cross-group friendships with immigrants and 
attitudes toward several minority groups, including groups that represented a small minority in the country (for further evidence in the 1990s, see Wilson, 1996).

Pettigrew and Tropp (2006) were able to locate 18 tests of the STE in 12 studies. Their results revealed that the STE was indeed a "real" phenomenon, with contact effects typically generalizing to groups uninvolved in the contact situation. Eller and Abrams (2004, Study 1) provided the first longitudinal evidence for the STE, although with a sample of only 34 participants. In this study, friendships with French people was associated with British university students' positive attitudes toward Algerians (a group linguistically similar to the French) 6 months later (for longitudinal evidence with a larger sample, see Van Laar, Levin, Sinclair, \& Sidanius, 2005). Robust evidence for the STE was provided by Tausch et al. (2010). The authors conducted a series of four studies (three correlational and one longitudinal), by considering over 4,000 participants in three contexts (Cyprus, Northern Ireland, and the United States) and a range of intergroup relationships, all consistently showing generalization to secondary outgroups. Further strong support for the STE was provided in a cross-sectional study by Schmid, Hewstone, Küpper, Zick, and Wagner (2012). By relying on a larger European survey, the authors examined a sample of over 7,000 participants from eight European countries and, considering immigrants as the primary outgroup, they found generalization of attitudes to Jews and homosexuals as the secondary outgroups.

Recent years have witnessed an increase in studies examining and providing support for the STE, by considering both adult (Schmid, Hewstone, \& Tausch, 2013; Schulz \& Taylor, 2018) as well as child (Berger, Benatov, AbuRaiya, \& Tadmor, 2016; Vezzali, Turner, Capozza, \& Trifiletti, 2018) and adolescent samples (Vezzali \& Giovannini, 2012; Zezelj, Milosevic-Dordevic, Van Niekerk, \& Pavlovic, 2020). Although most of the studies focused on generalization between ethnic groups, there also is evidence of the STE toward religious groups (Tausch et al., 2010) and individuals with disability (Barr \& Bracchitta, 2015).

In this review, we were able to locate 43 studies of the STE (see Tables 1-3), showing evidence for its existence. Research has been mainly conducted in Europe (26 studies) and North America (10 studies), whereas research in Asia and South America (three studies in each) and in Oceania (one study) has been scarce. We were not able to locate any study conducted in Africa.

Evidence that contact effects generalize to secondary outgroups has been obtained mainly with correlational (Brylka, Jasinskaja-Lahti, \& Mähönen, 2016; Hindriks et al., 2014; Pettigrew, 2009; Vezzali et al., 2019, 24 studies, see Table 3), but also with longitudinal (Bowman \& Griffin, 2012; Mähönen \& Jasinskaja-Lahti, 2016; Tausch et al., 2010, Study 4; Turner \& Feddes, 2011; Van Laar et al., 2005, seven studies, see Table 2), and experimental methodologies (Harwood et al., 2011; Jasinskaja-Lahti et al., 2020; Li et al., 2016; Shook et al., 2016; but see Mark \& Harris, 2012, 13 studies see Tables 1; note that the study by Van Laar et al., [2005] has been included both as an experimental and a longitudinal study, see Tables 1 and 2).

\section{4 | METHODOLOGICAL ISSUES}

There are at least three methodological issues that can challenge the confidence in the results that support the STE. First, mirroring the more general contact research that is largely correlational, it is important to address the issue of causality. Specifically, the question that arises is, is it the intergroup contact that leads to reduced prejudice toward secondary outgroups or is it that individuals who are less prejudiced toward a wide range of groups seek out more 


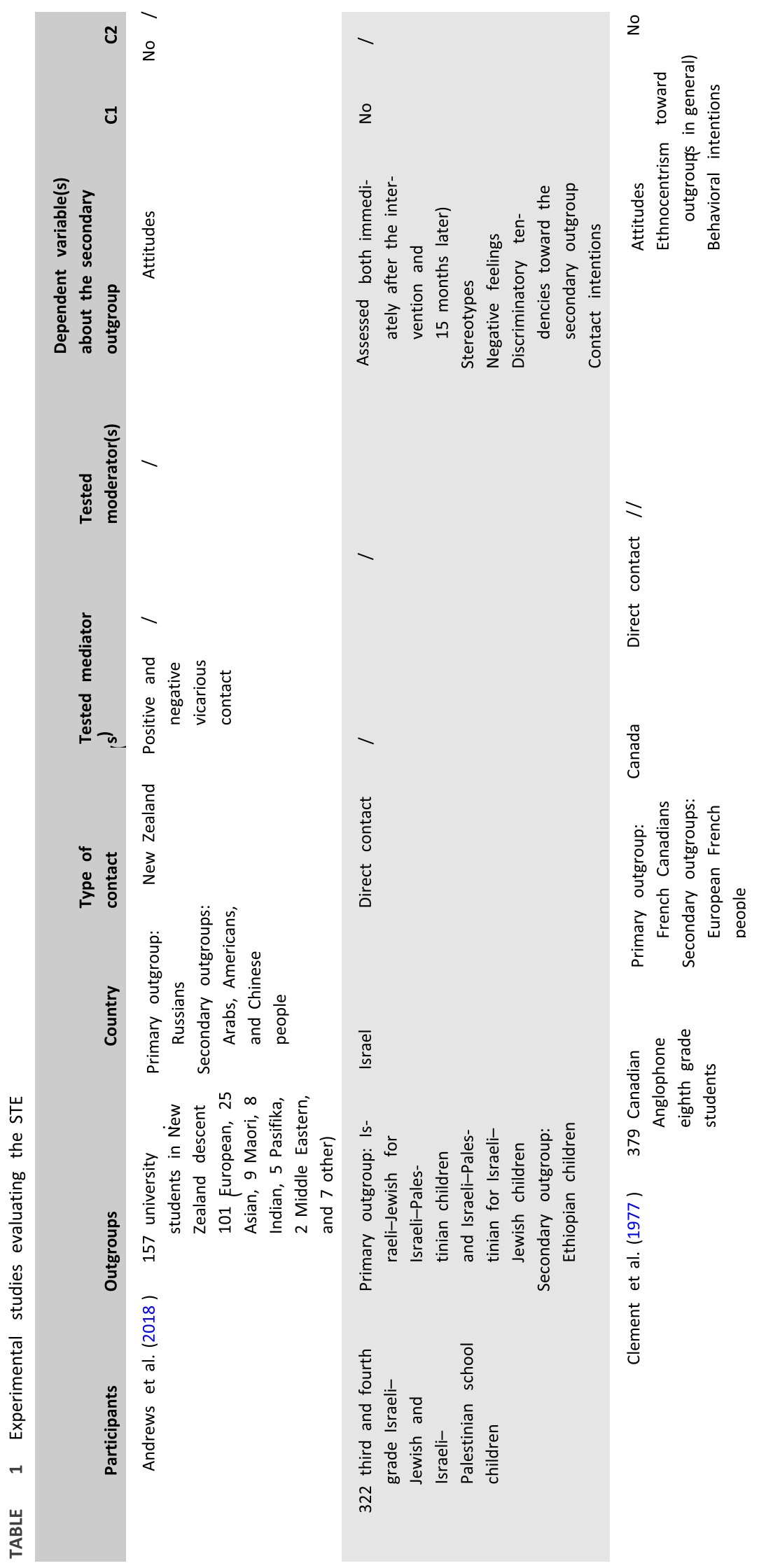




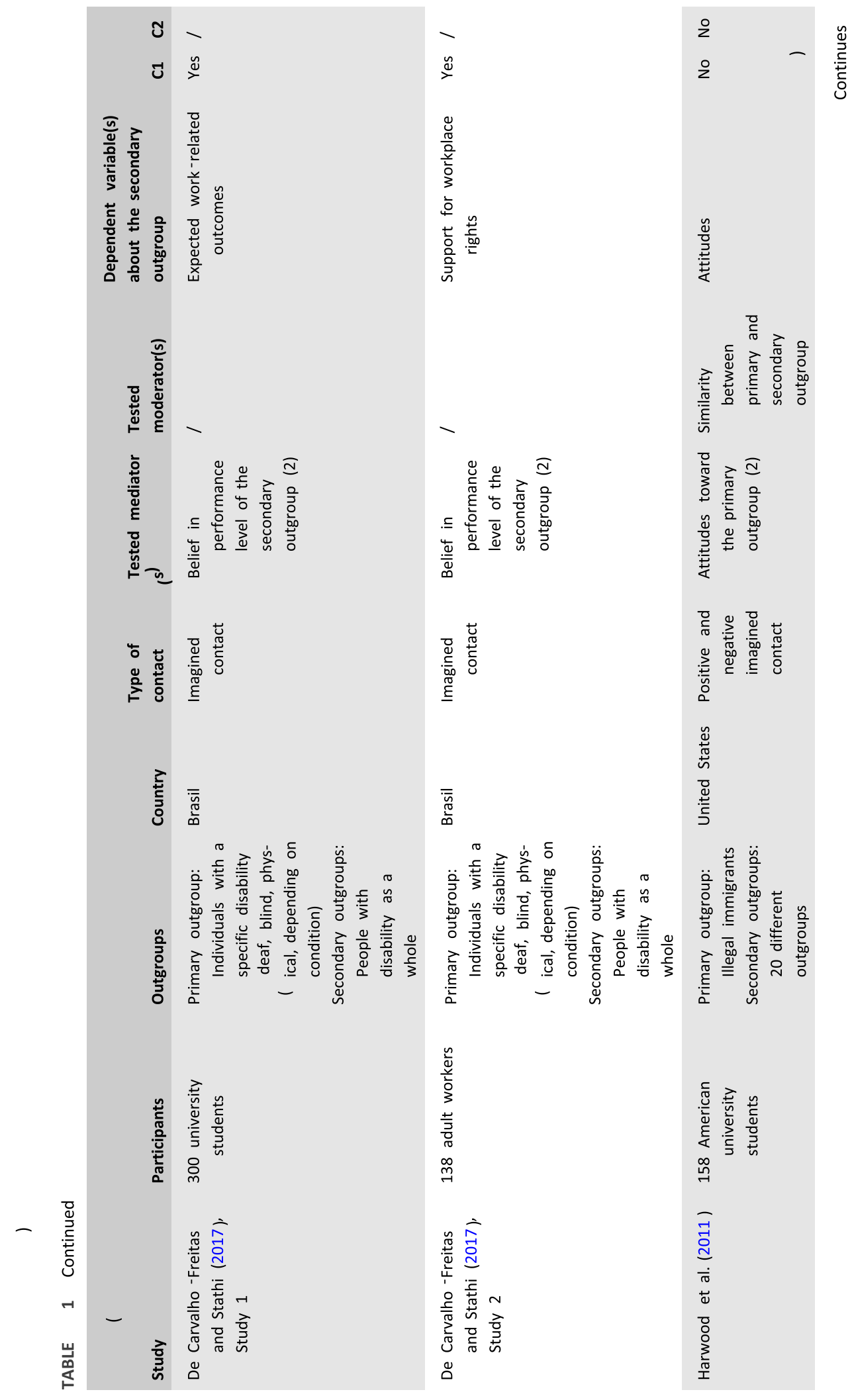




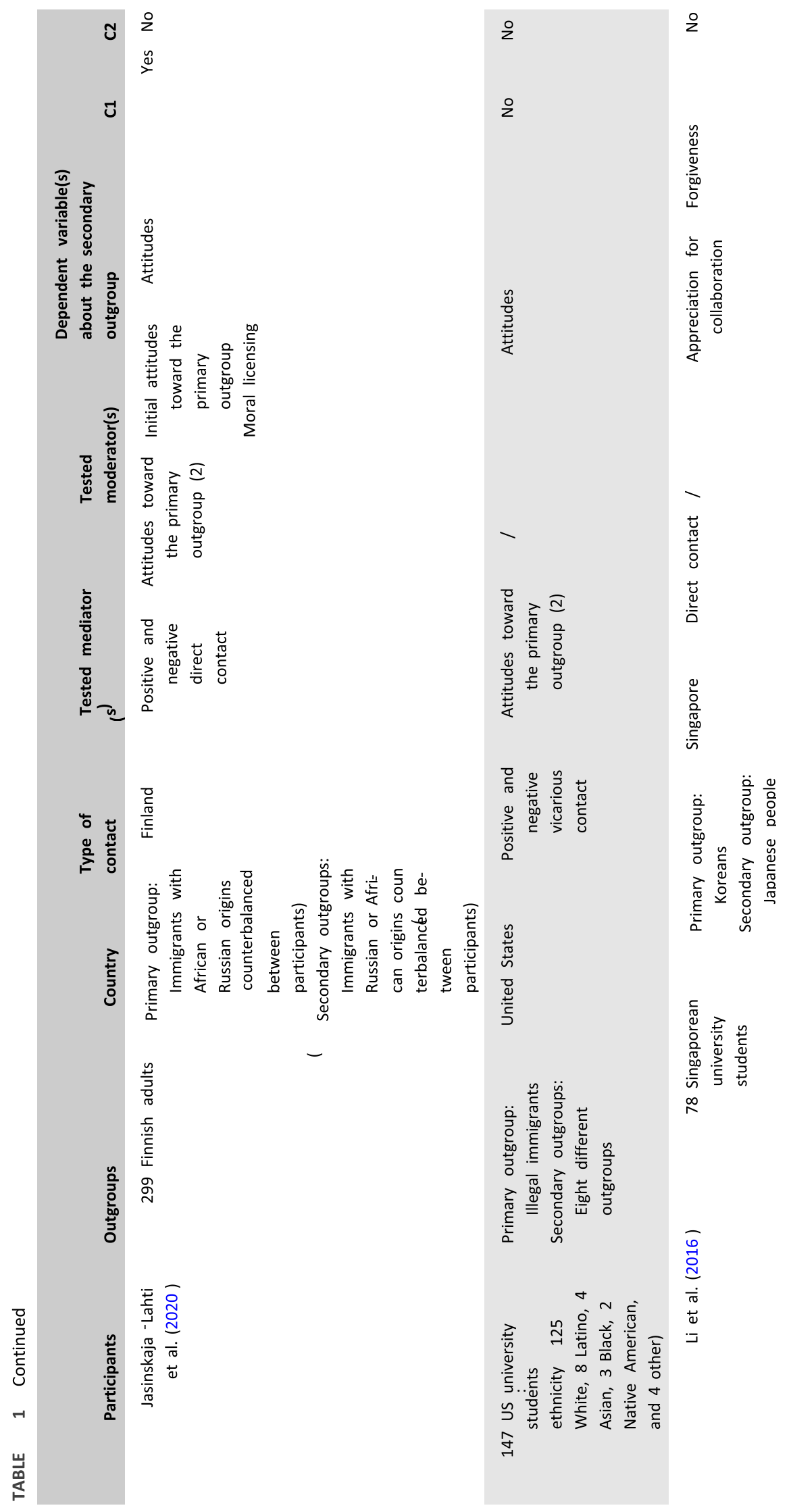


产

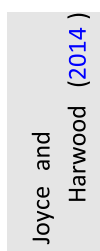

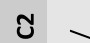

운

ㄷ 울

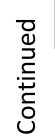

$\frac{n}{\frac{0}{0}}$

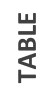




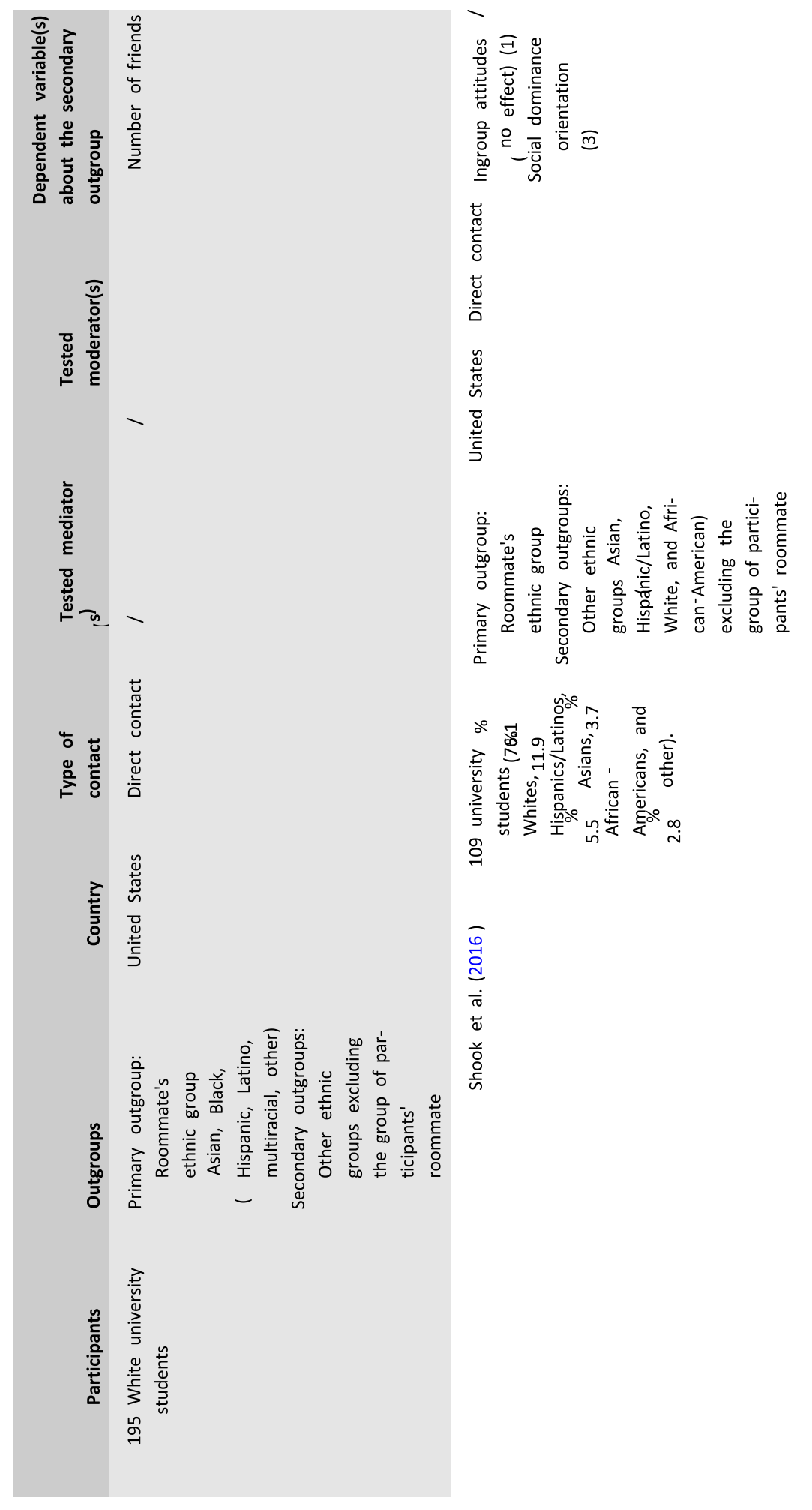




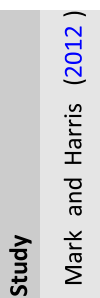





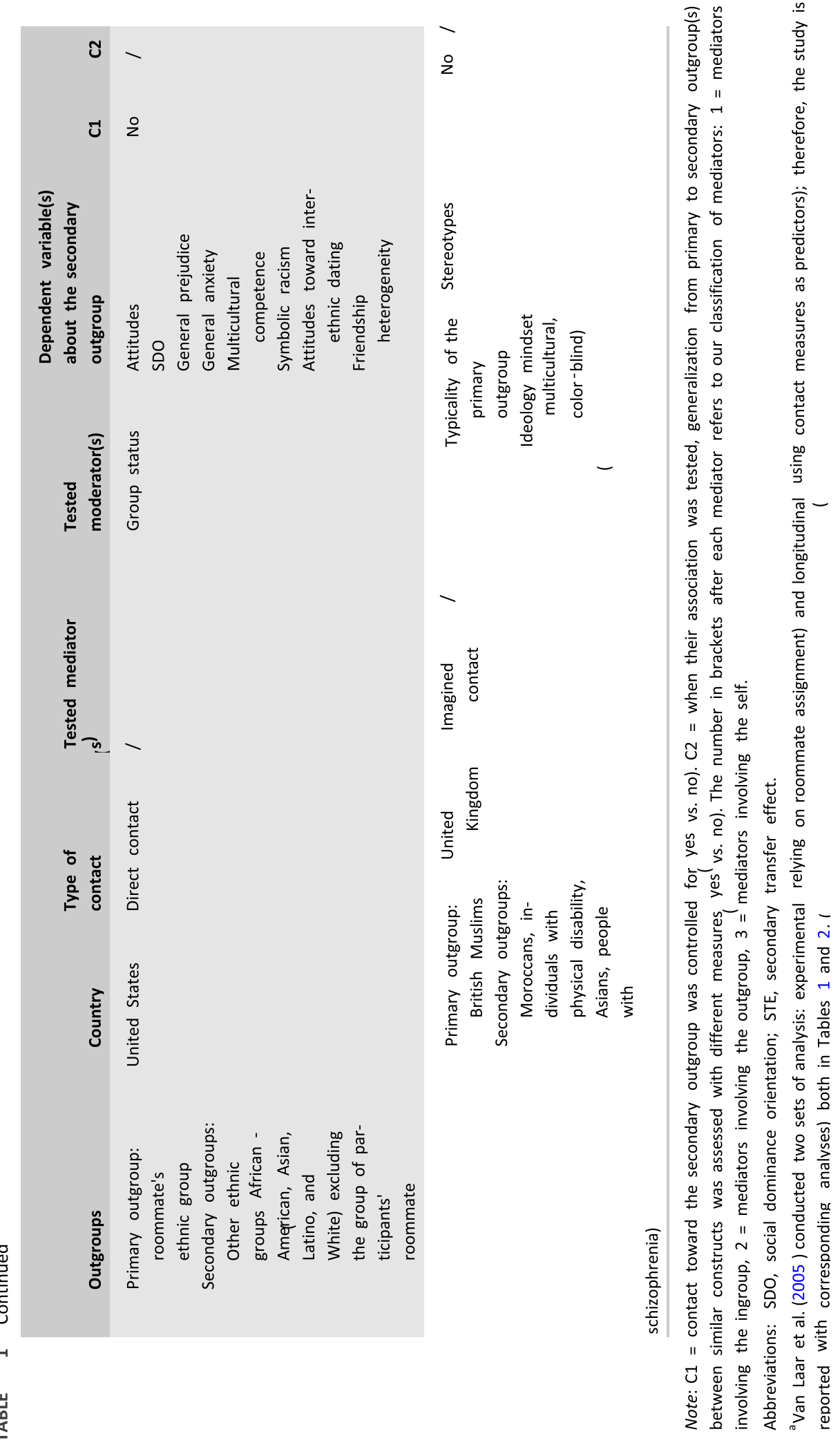




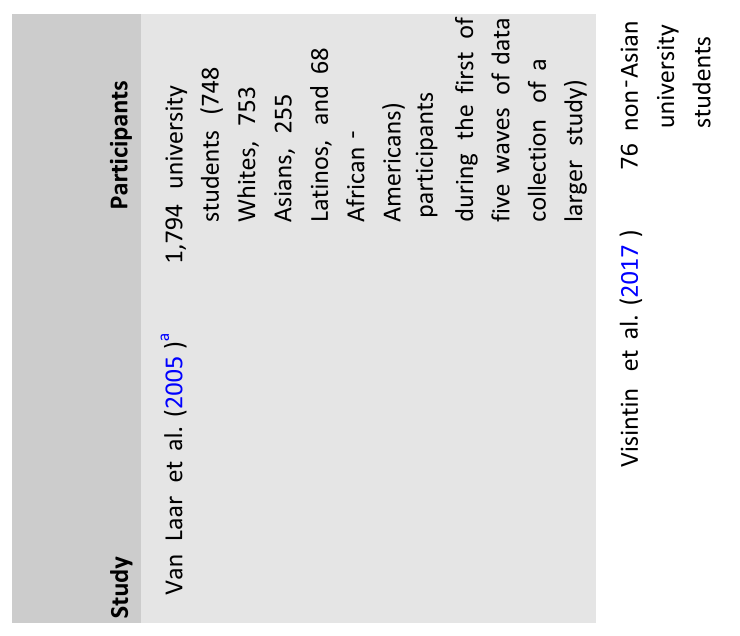





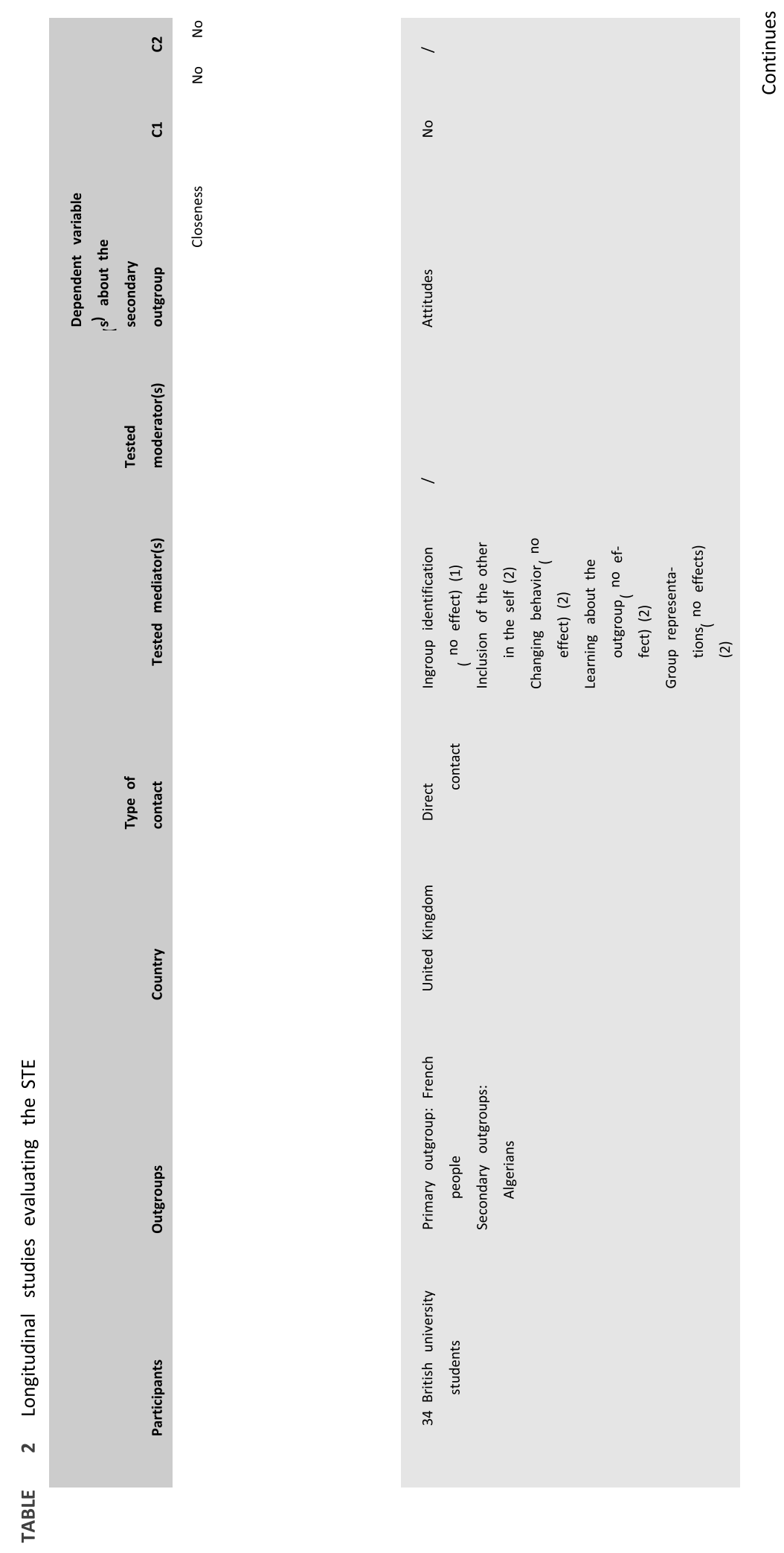




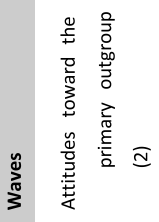

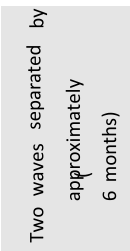

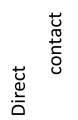

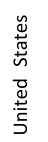

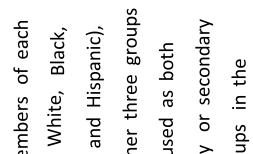

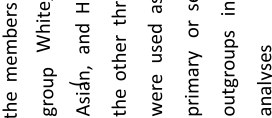

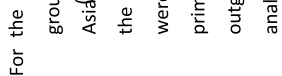

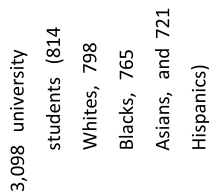

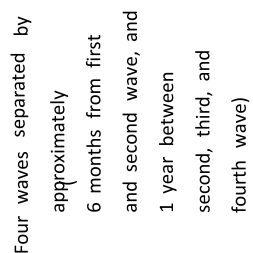

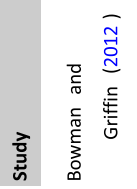

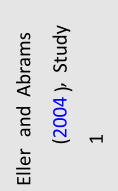




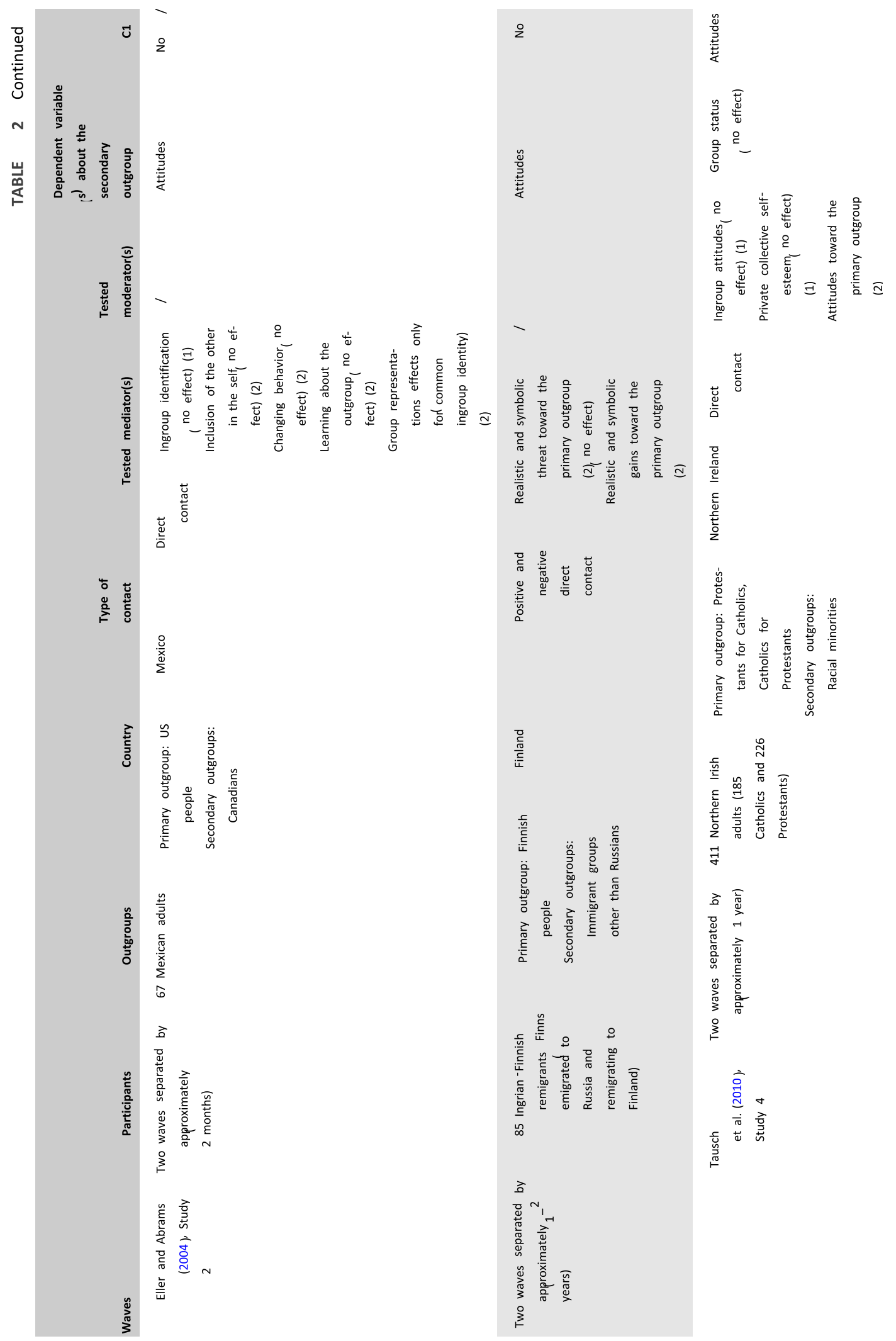




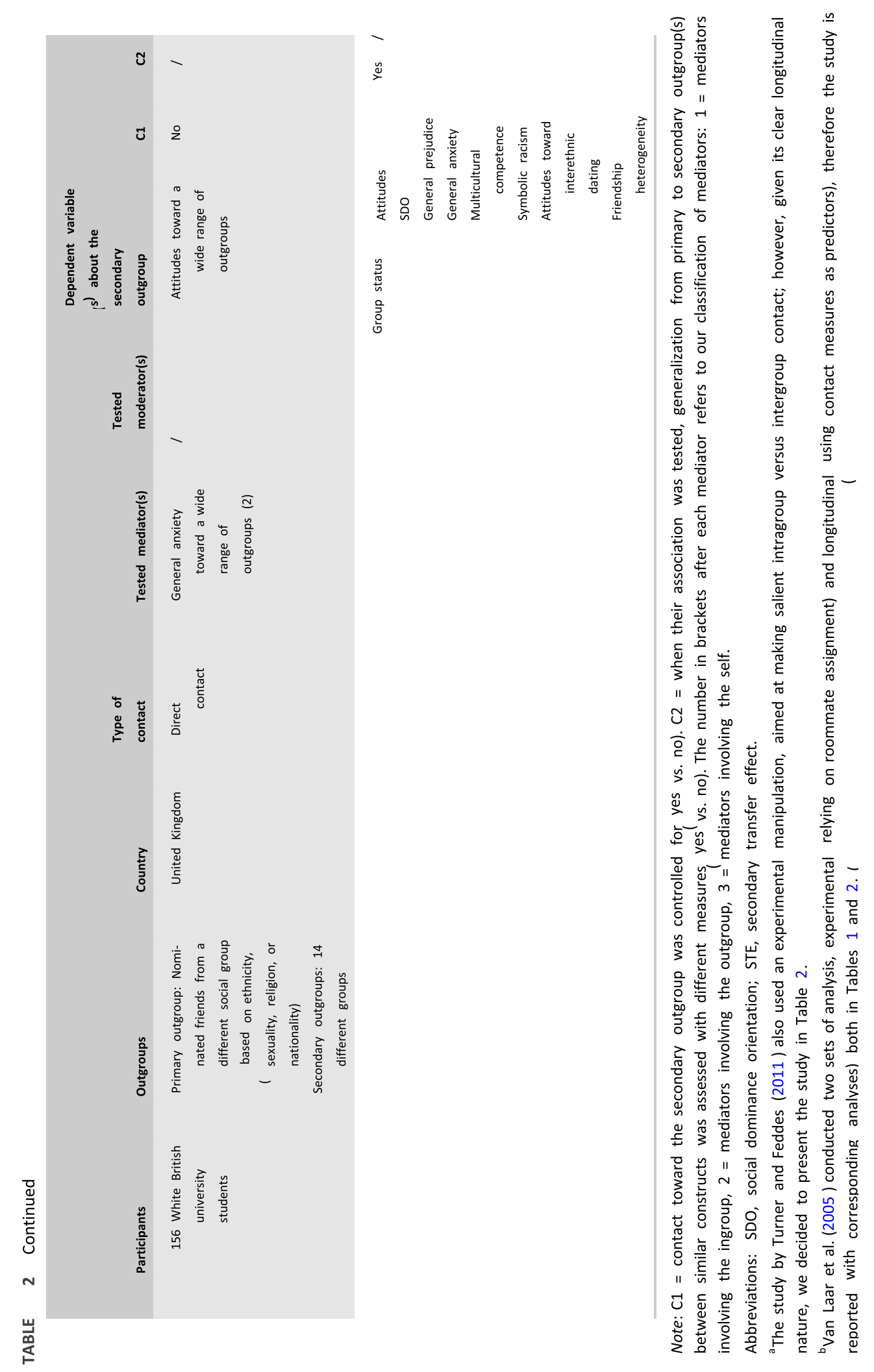



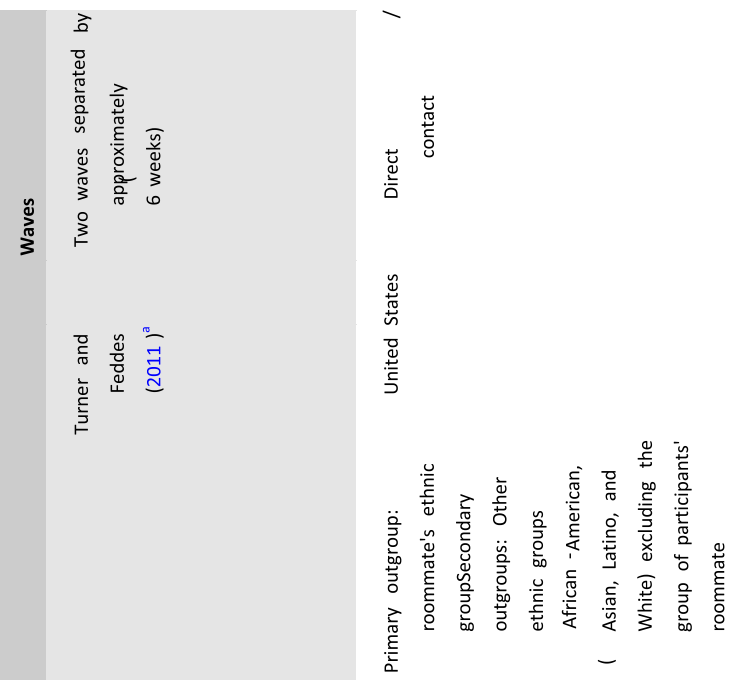

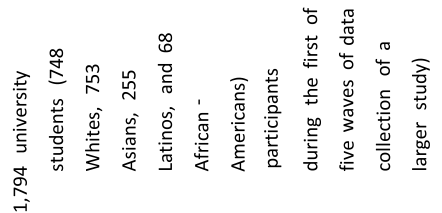

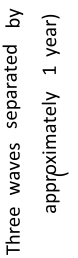

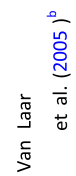

高 



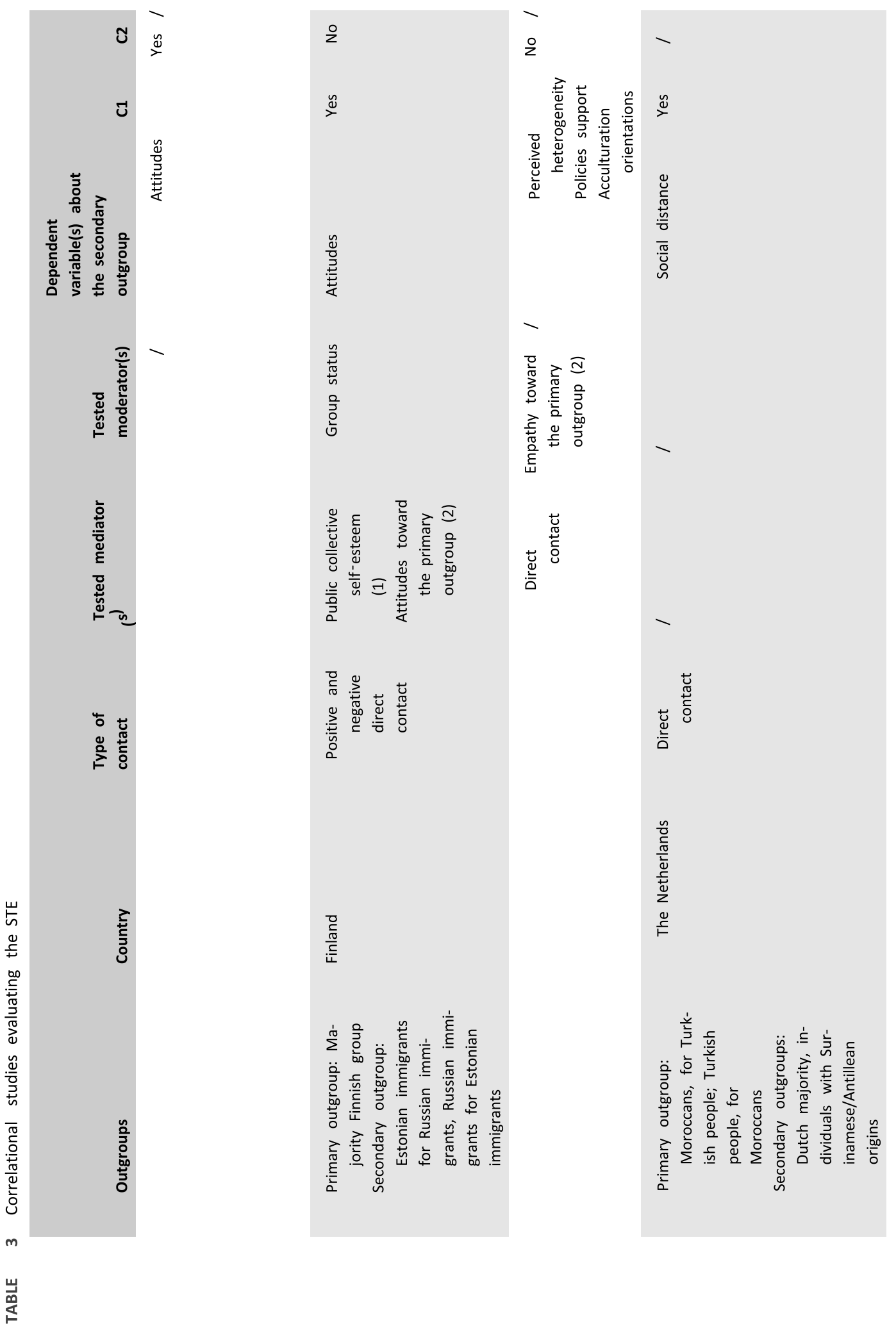




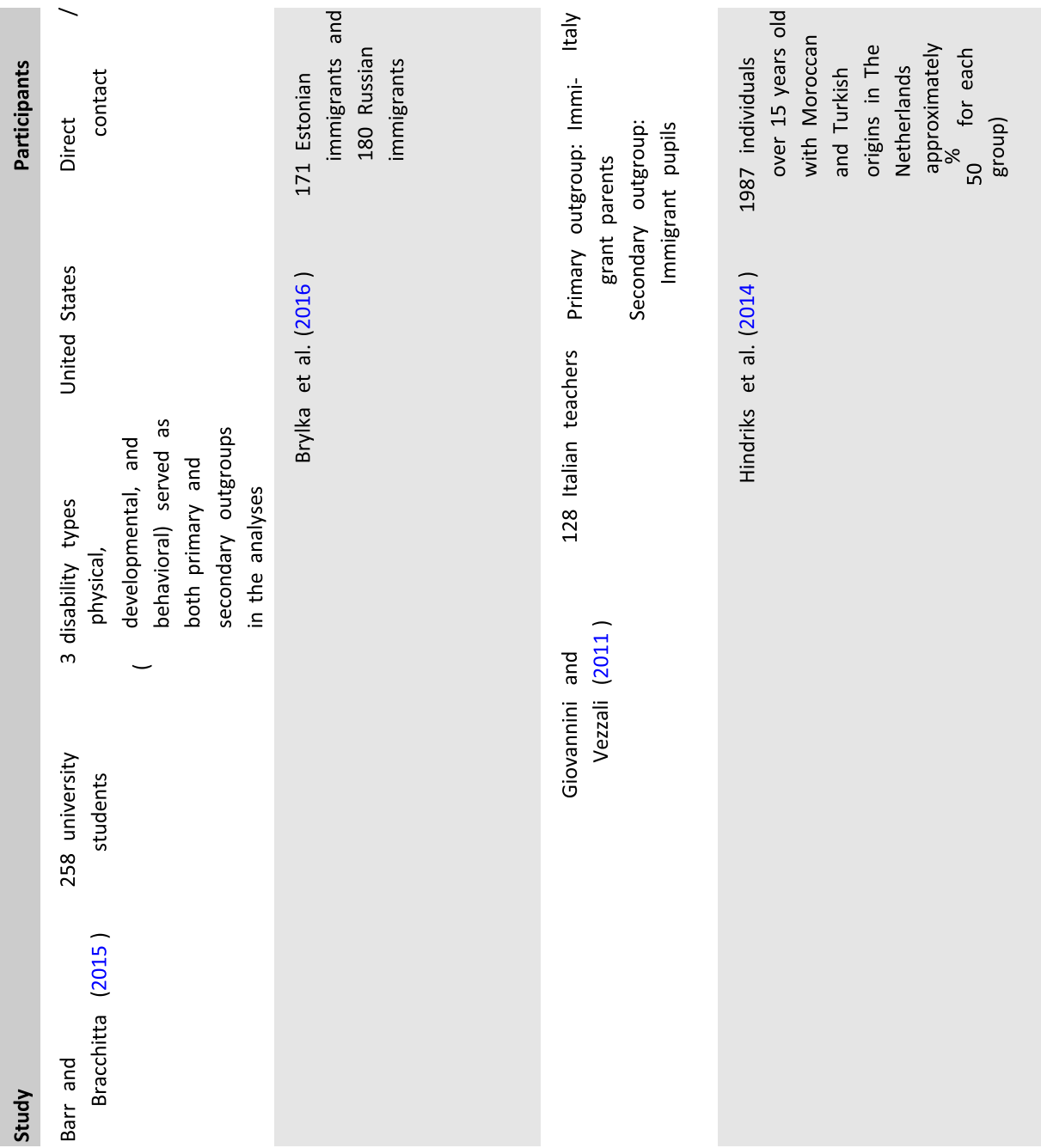




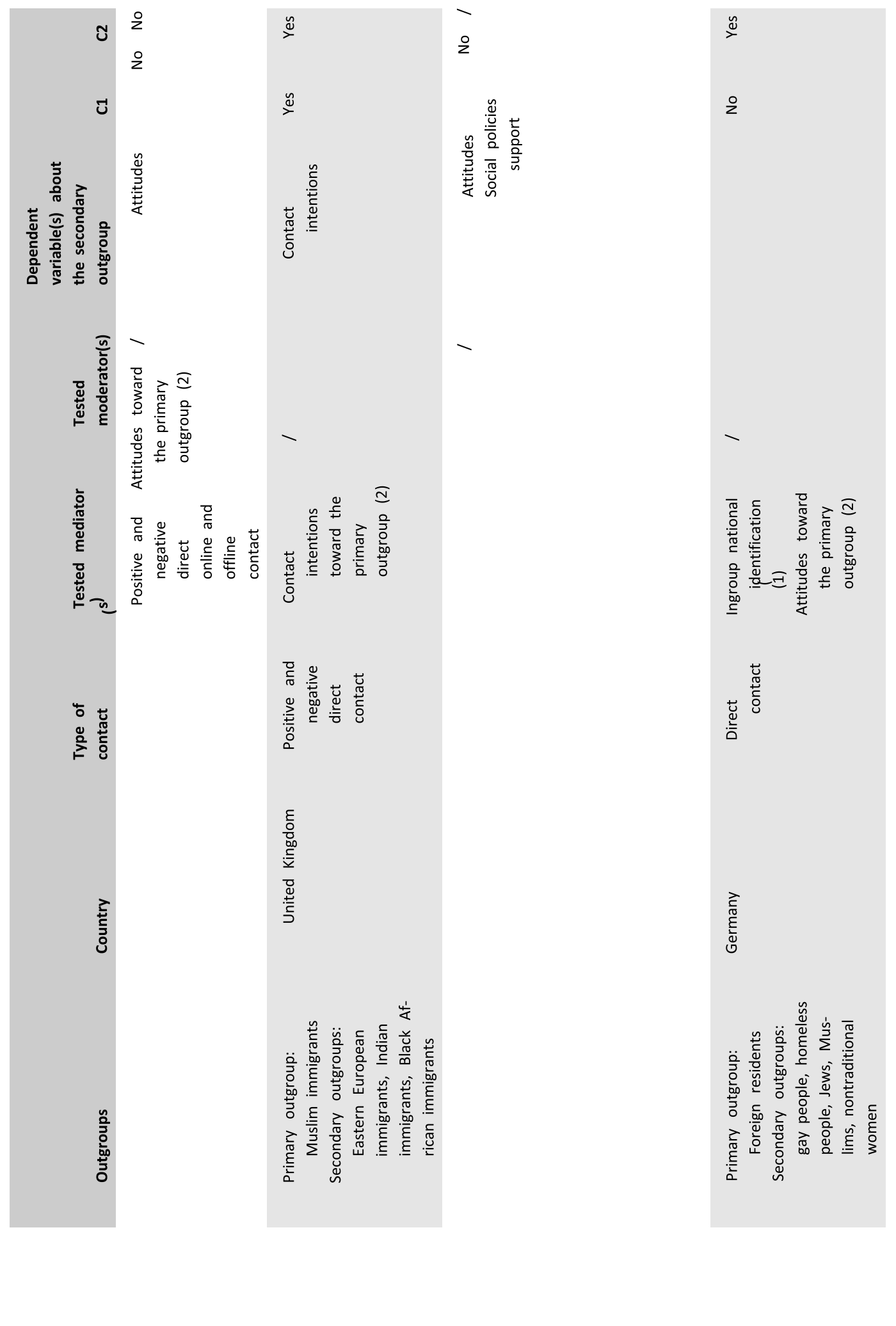




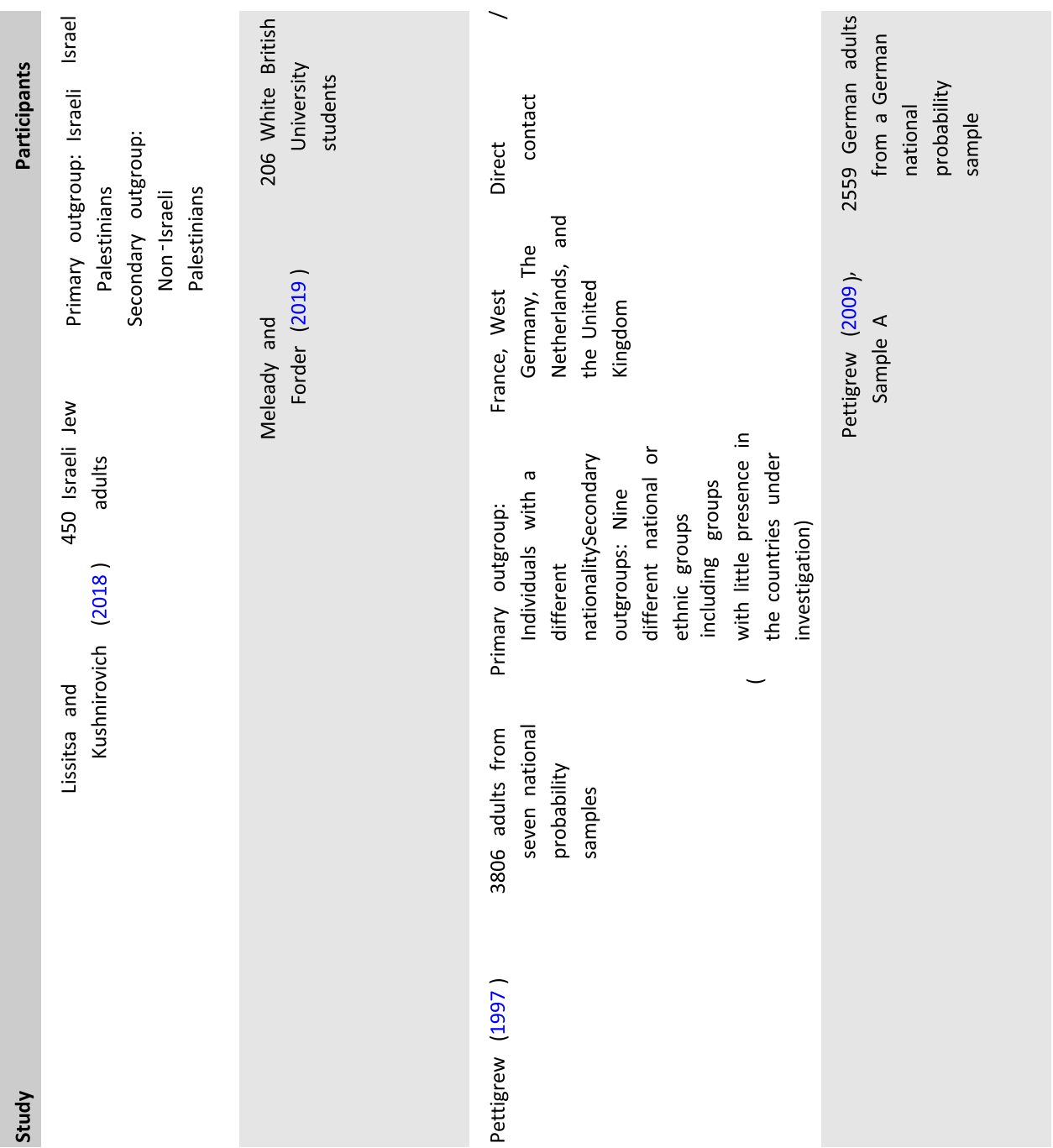


$-\stackrel{0}{\stackrel{0}{c}}$ 


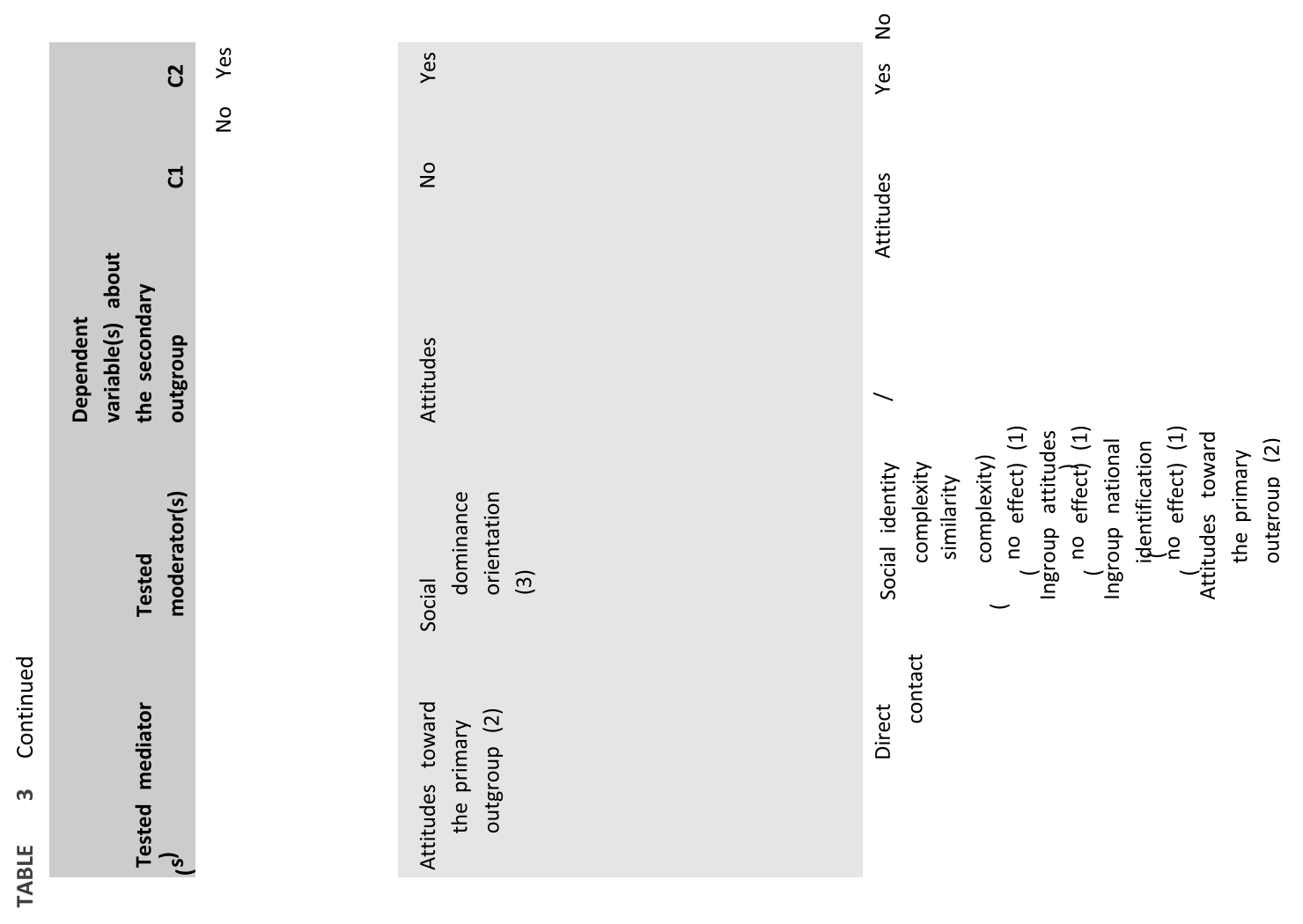




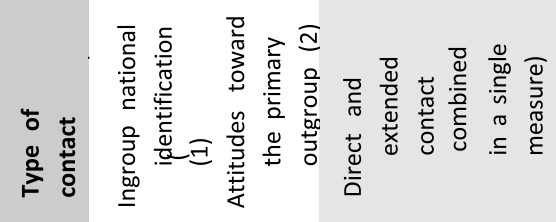

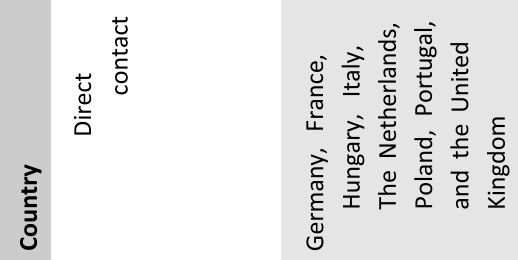

离

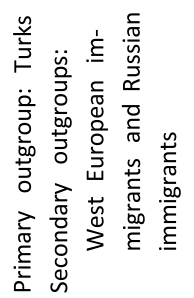

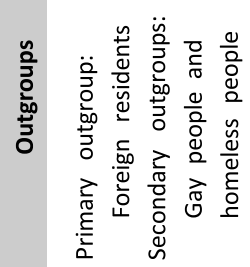

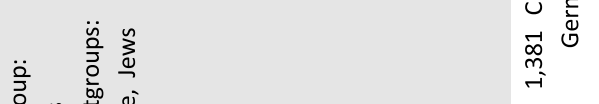

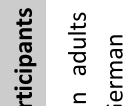

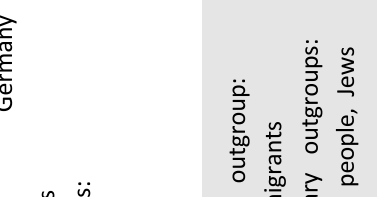

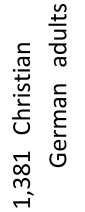

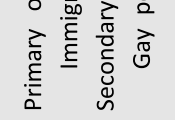

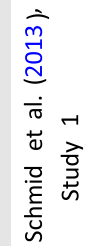

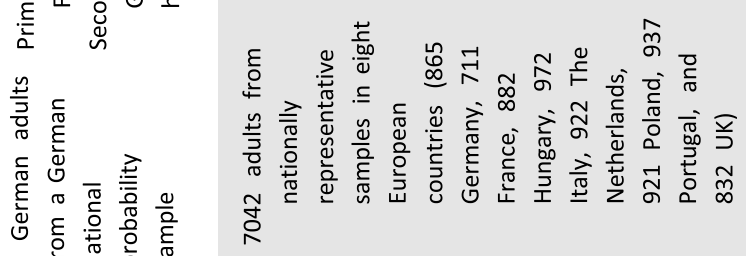
ก

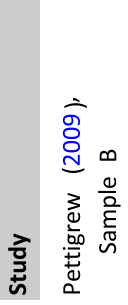

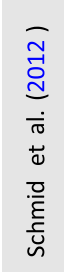

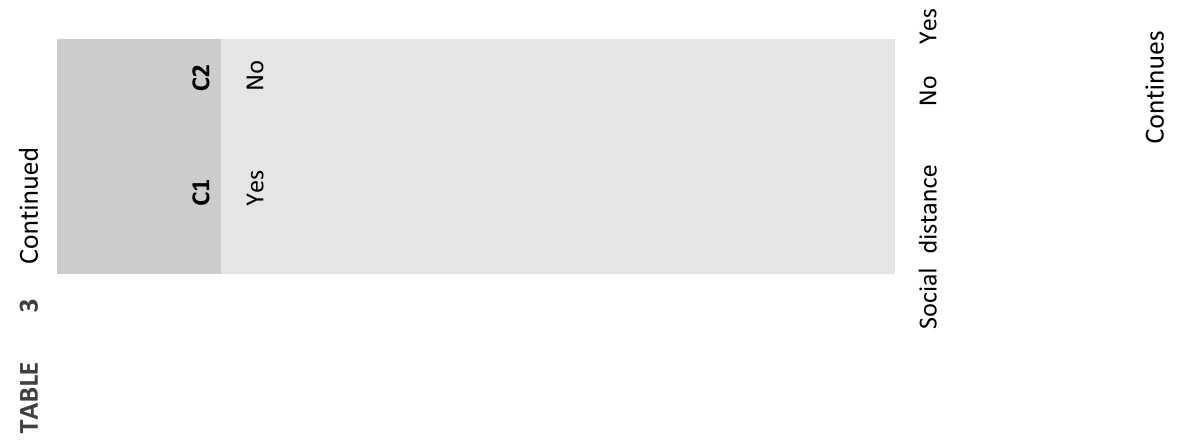




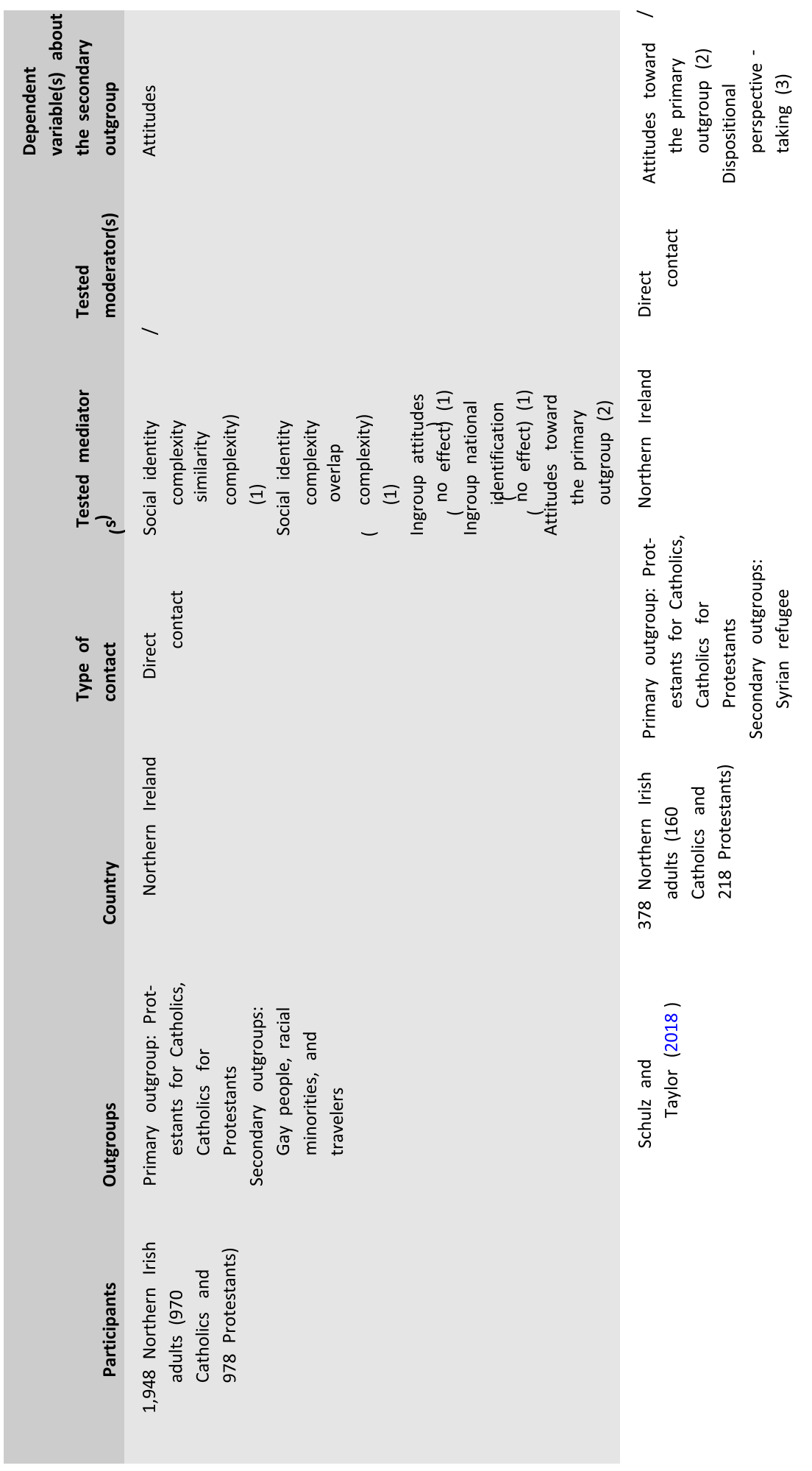




$$
\begin{aligned}
& \text { in } \\
& \text { 르 } \\
& \text { पै } \\
& \text { 을 론 } \\
& \text { 흘 }
\end{aligned}
$$



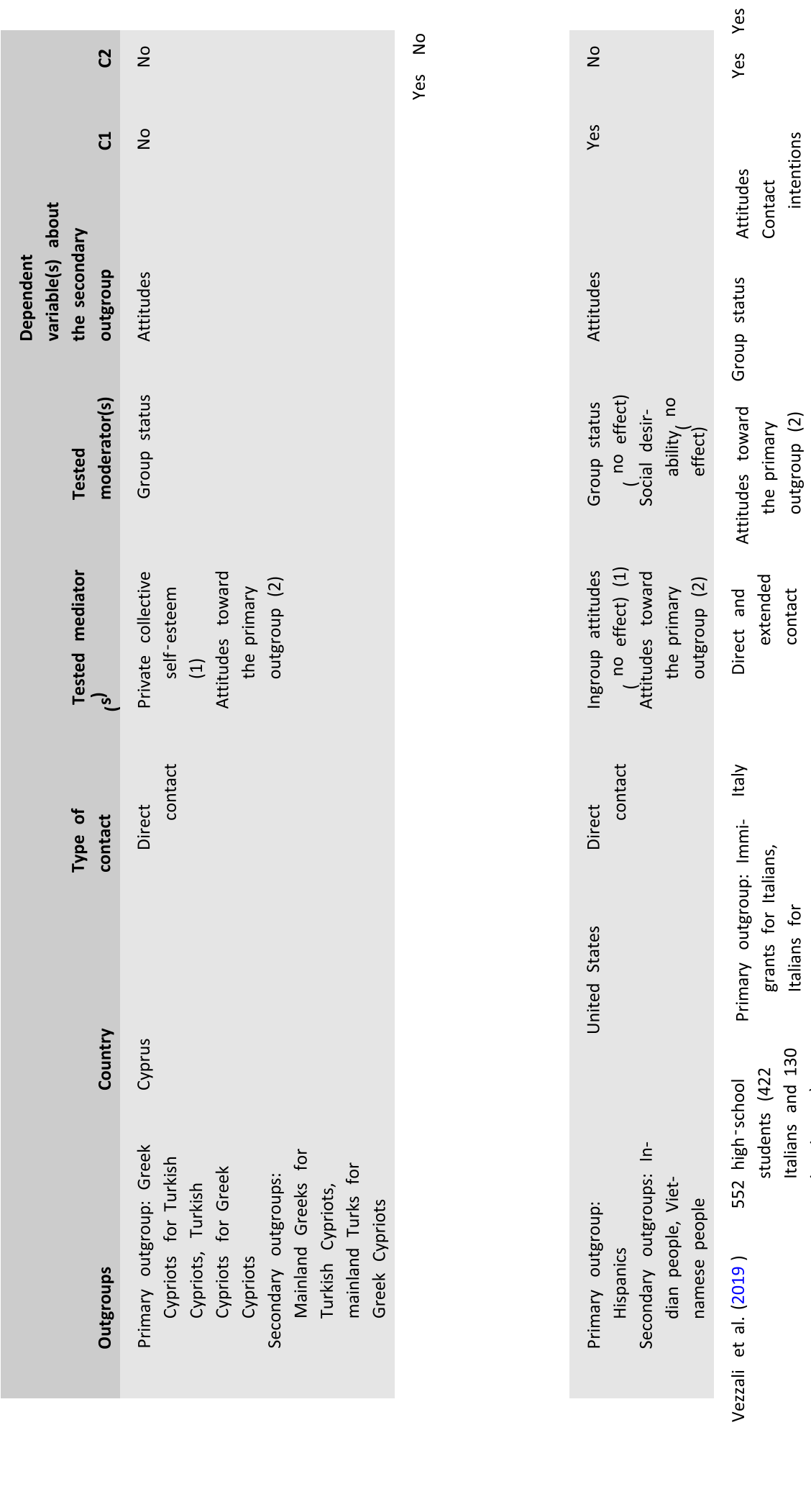

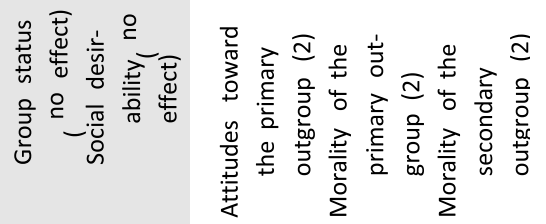

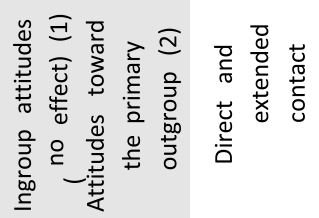
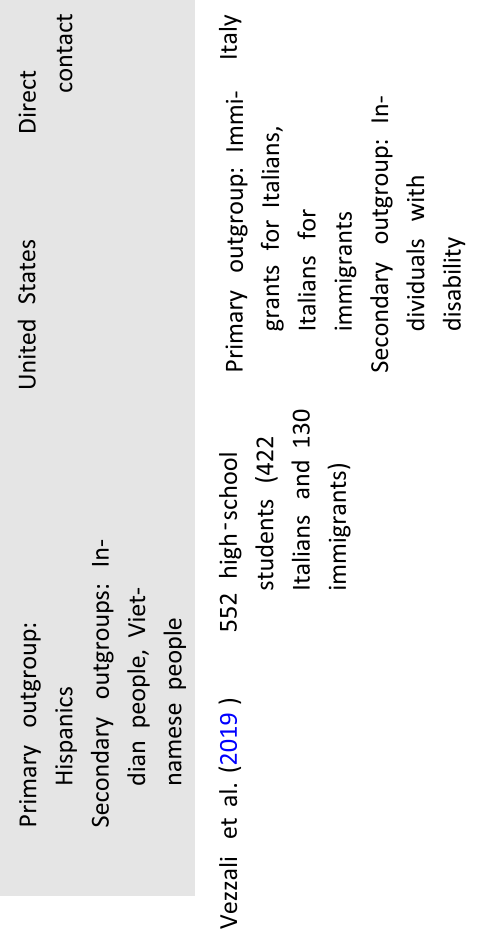

宸 

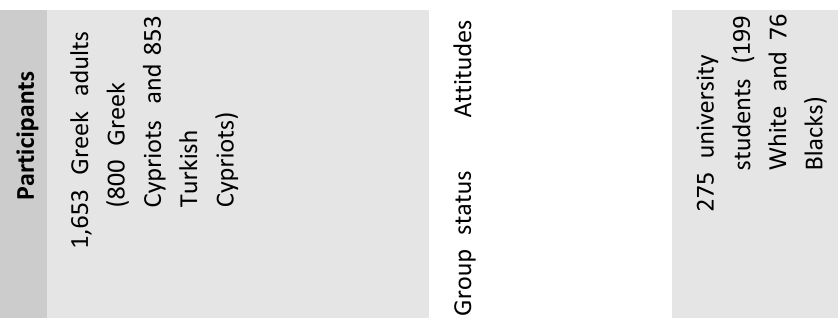

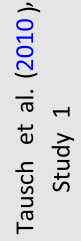
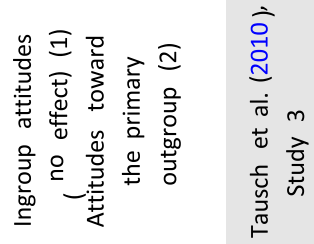

苋

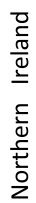

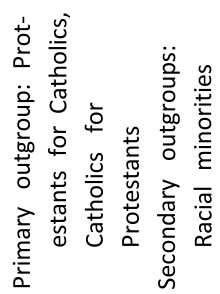

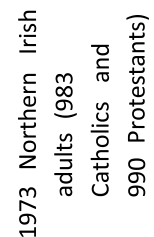

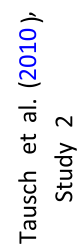




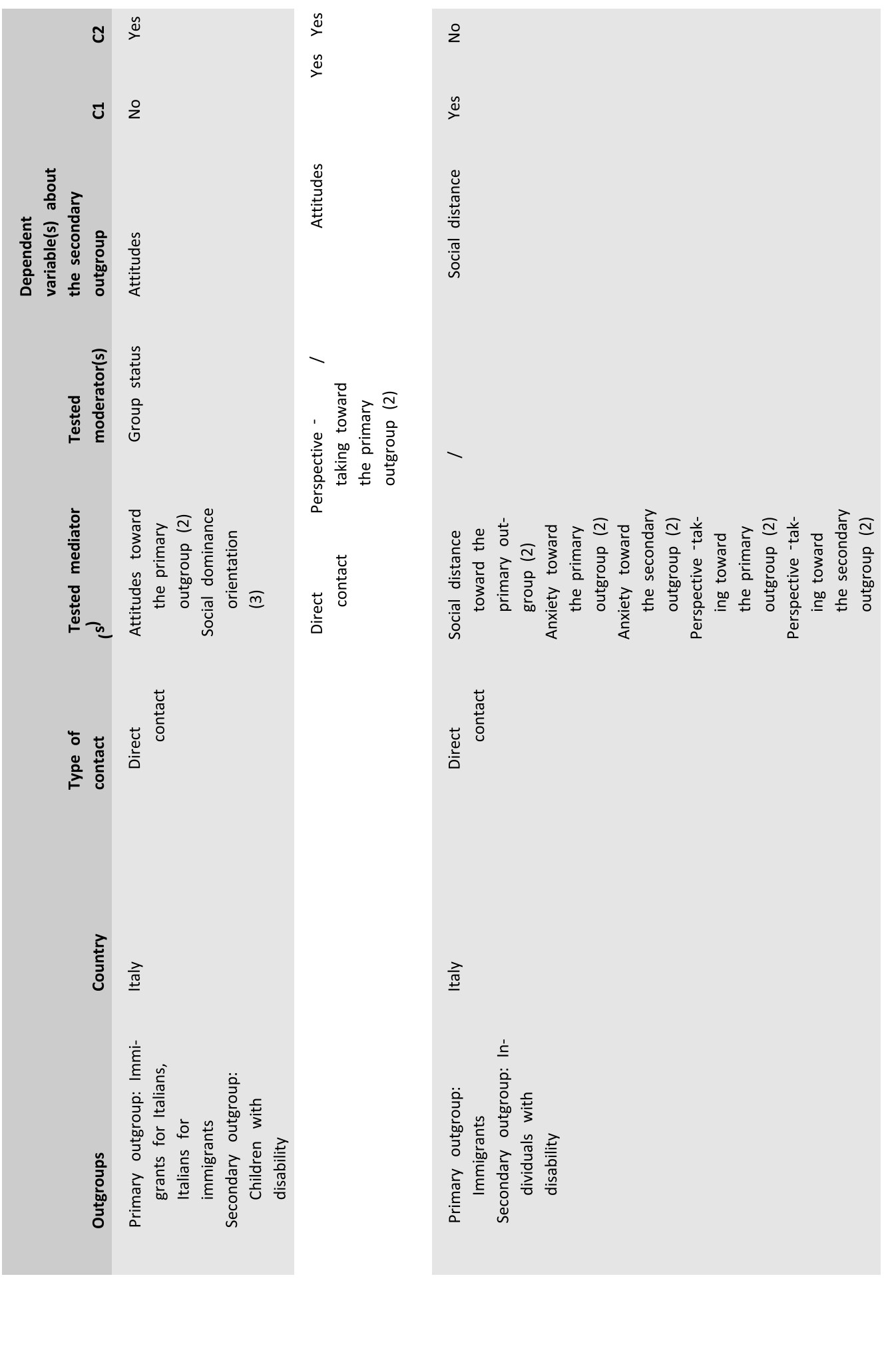




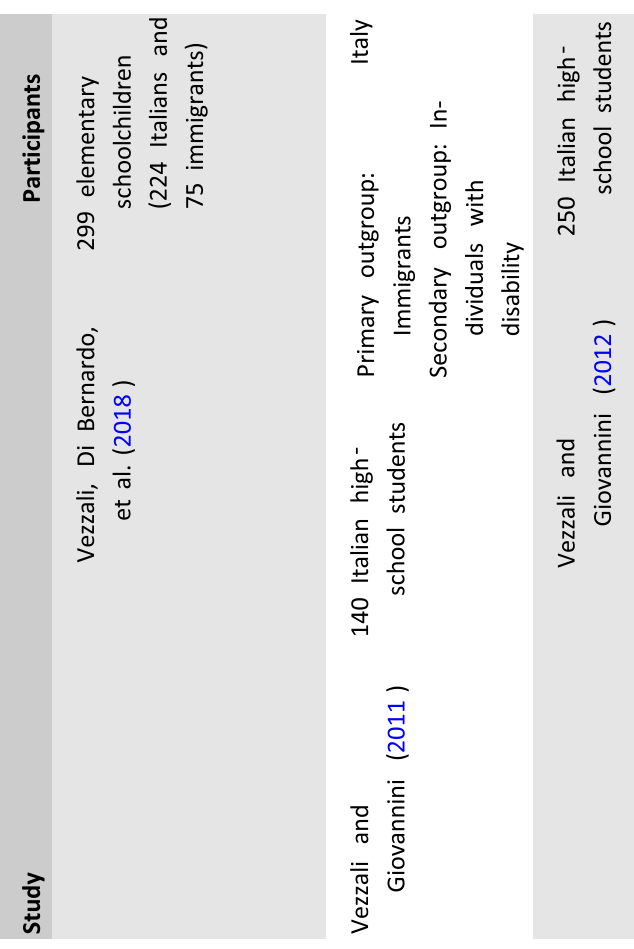




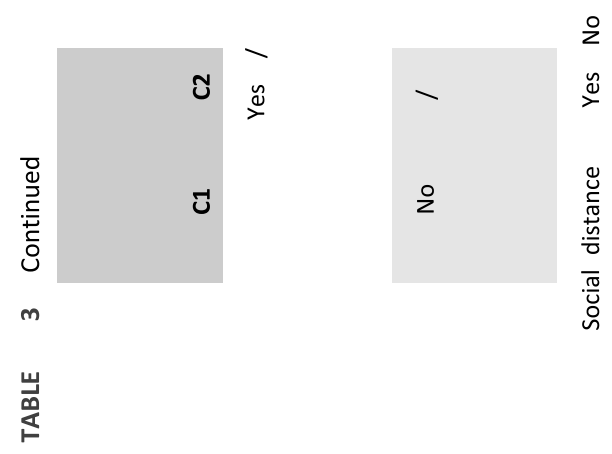




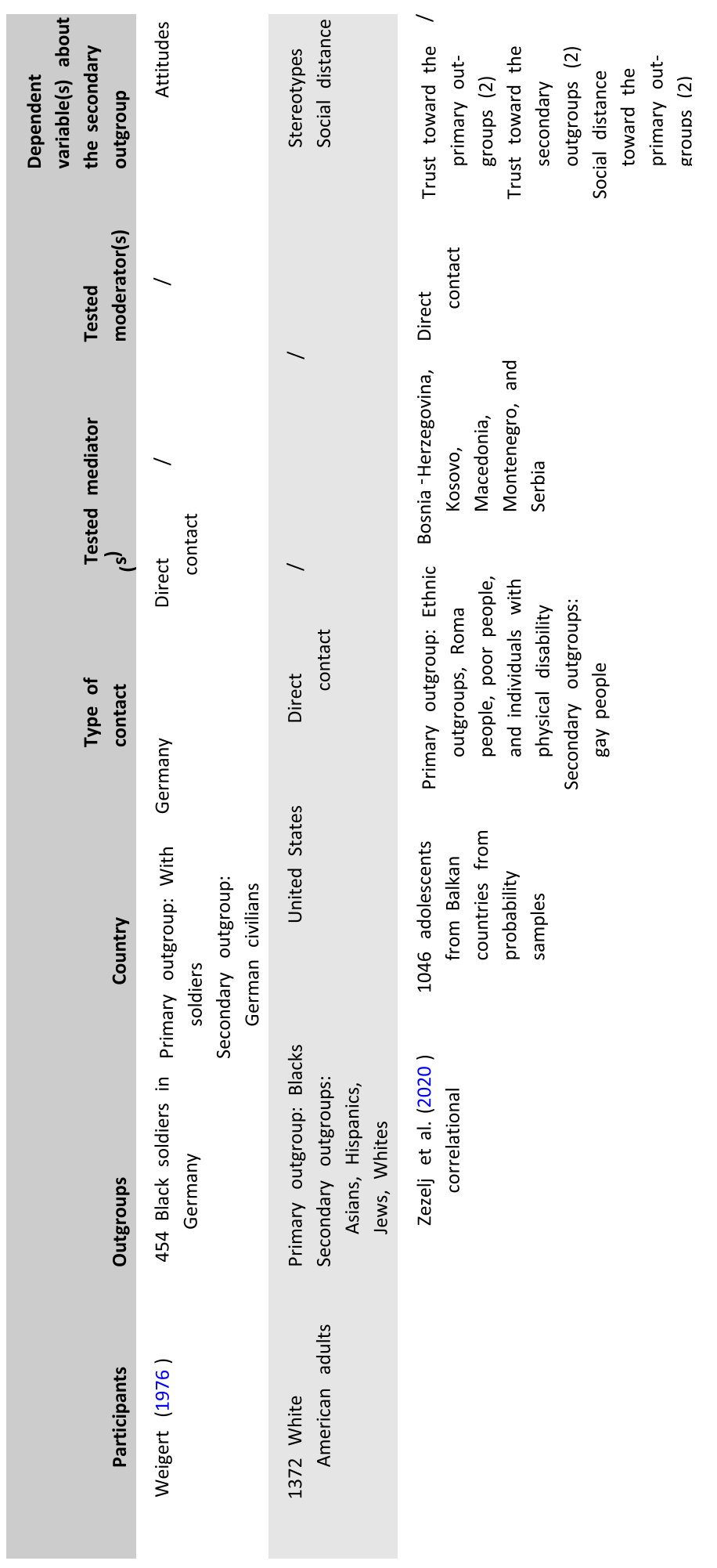




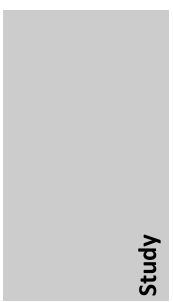

5
8
0
5
0
$\frac{0}{3}$

훌 


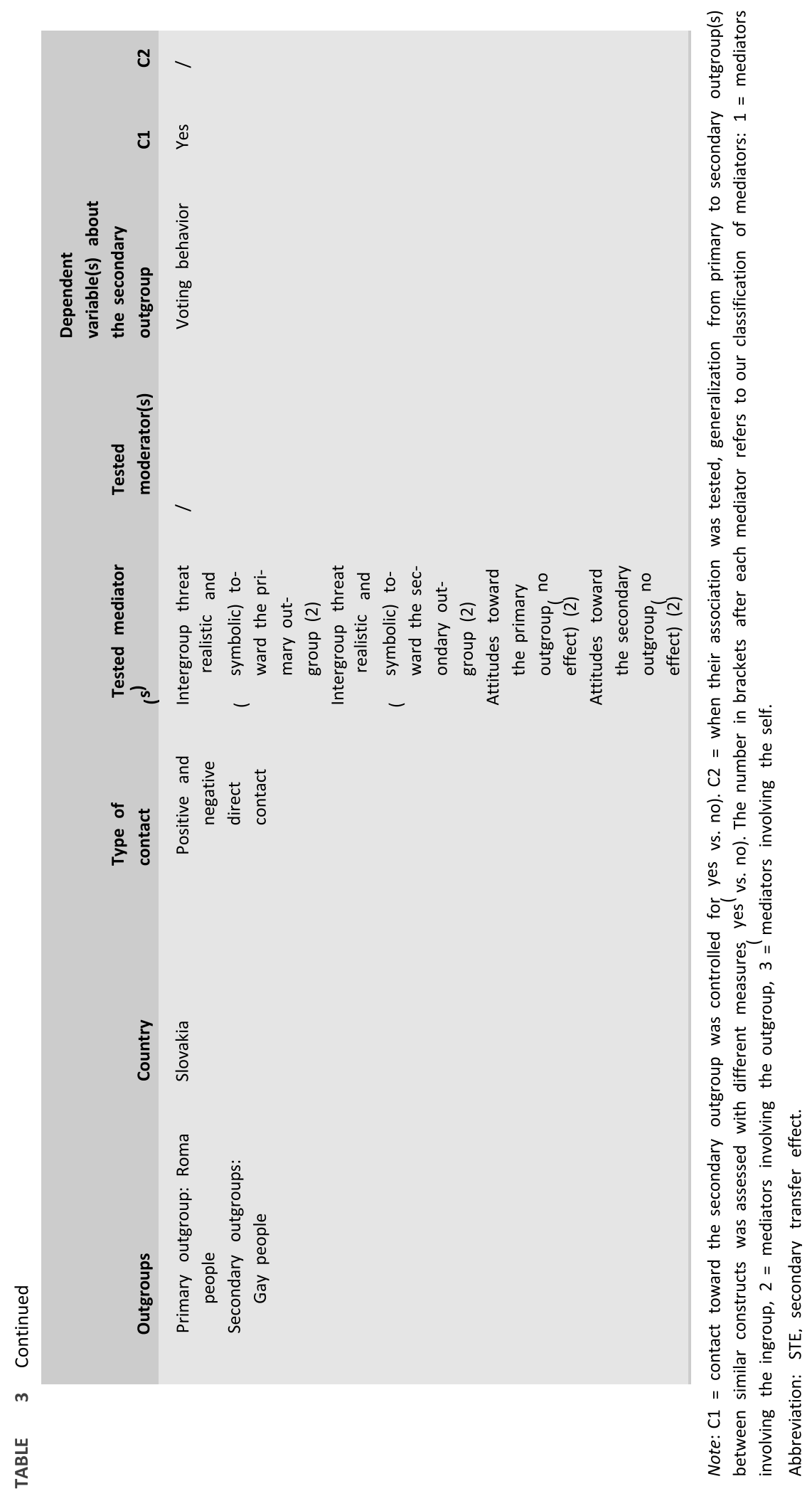




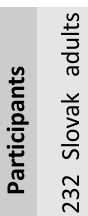

$$
\begin{aligned}
& \text { 高 } \\
& \text { 늄 } \\
& \text { 듀 } \\
& \text { วิ }
\end{aligned}
$$


intergroup contact? Evidence from longitudinal (Eller \& Abrams, 2004, Study 1; Mähönen \& Jasinskaja-Lahti, 2016; Tausch et al., 2010, Study 4; Turner \& Feddes, 2011; Van Laar et al., 2005) as well as from experimental studies (Harwood et al., 2011; Jasinskaja-Lathi et al., 2020) support the contact-attitude path, although the process is likely to be bidirectional, as indicated in the broader contact literature (e.g., Binder et al., 2009).

A related issue that needs consideration is that individuals with more contact with the primary outgroup may be more open to diversity and, as a consequence, have more contact with secondary outgroups. In this case, the STE might be a product of contact with secondary outgroups, rather than of contact with the primary outgroup that generalizes beyond the contact situation. In Tables 1-3, we provided indications about this methodological limitation, by indicating for each study whether contact with the secondary outgroup(s) was controlled for. Ruling out this concern, according to our tables, 19 studies statistically controlled for contact with the secondary outgroup and still provided evidence for the STE (e.g., Tausch et al., 2010, Studies 2-4; Van Laar et al., 2005; Vezzali \& Giovannini, 2012; Weigert, 1976; Zezelj et al., 2020).

A further methodological issue concerns the measures used to assess attitudes toward primary and secondary outgroups. Some studies used similar scales to assess attitudes toward the primary and secondary groups, therefore inflating not only the risk of shared method variance but also the likelihood for socially desirable responding (e.g., Schmid et al., 2013; Shook et al., 2016). In Tables 1-3, we included a column indicating for each study whether (wherever relevant) different measures were used to assess attitudes toward both primary and secondary outgroups. Addressing this concern, eight studies demonstrated the existence of the STE by using different measures of attitudes toward primary and secondary outgroups (e.g., Schmid et al., 2012; Vezzali, Di Bernardo et al., 2018). Especially strong support is provided by studies that used different conceptual measures for primary and secondary outgroups, for instance, assessing generalization from attitudes toward the primary outgroup to contact intentions toward the secondary outgroup (Vezzali et al., 2019).

In addition, the STE has also emerged when controlling for strong predictors of prejudice, such as social dominance orientation (SDO), demonstrating the robustness of the effect (Vezzali \& Giovannini, 2011).

In sum, current research on the STE has considered and addressed various methodological limitations, and provided evidence to exclude that the STE is inflated by such constraints.

\section{5 | MEDIATORS OF THE SECONDARY TRANSFER EFFECT}

We believe an examination of the processes underlying the STE is especially relevant for two main theoretical reasons. First, it allows to understand how to reduce prejudice beyond the outgroup one has contact with, therefore potentially impacting on how to tackle generalized prejudice. Second, research has yet not provided evidence for mediators specific to the STE effect, explaining how the effects of contact can spread to affect prejudice in the wider society. This also implies a conceptual difference between mediators of the effects of contact on the primary outgroup (the "classic" contact effect) and mediators of effects toward secondary outgroups.

While traditional mediators of contact focus on the outgroup (e.g., contact reduces intergroup anxiety and improves empathy felt toward the primary outgroup), mediators of the STE involve different centers of attention. We distinguish here between three categories of mediators. One set of mediators refers to changes in outgroup perceptions. A second set relates to changes in how the ingroup is represented. A third set concerns changes in the self, which may impact on intergroup relations more generally. This distinction, underlying a theoretical model of processes driving the STE, is presented in Figure 1. Largely supported by research findings, we believe that the three types of processes underline the STE stemming from contact. 


\section{1 | Mediators involving the outgroup}

\subsection{1 | Outgroup attitudes}

Attitude generalization is by far the most studied mediator of the STE and has received ample empirical support. This mechanism is based on the idea that contact with the primary outgroup improves attitudes toward the primary outgroup; in turn, these attitudes mediate the relationship between contact with the primary outgroup and attitudes toward the secondary outgroup. Pettigrew (2009) provided the first evidence for this mechanism in a crosssectional study. Germans who had contact with foreigners showed less prejudice toward gay and homeless people via reduced prejudiced toward foreigners. This study, however, did not control for prior contact with the secondary outgroups. Support for attitude as the mediating mechanism was provided by Tausch et al. (2010), in four studies (also when using longitudinal analyses, Study 4). In these studies, the authors controlled for contact with the secondary outgroup (Studies 2-4), included a measure to statistically control for social desirability (Study 3), and tested other concurrent mediators, providing, therefore, a stringent test for the attitude generalization mechanism.

In recent years, further evidence from cross-sectional studies has demonstrated the robustness of the attitude generalization mediating effect (Bowman \& Griffin, 2012; Brylka et al., 2016; Jasinskaja-Lahti et al., 2020; Schmid et al., 2012, 2013; Schulz \& Taylor, 2018; Vezzali, Di Bernardo, et al., 2018, 2019; Vezzali \& Giovannini, 2011, 2012; Zezelj et al., 2020; for evidence of generalization via contact intentions, see Meleady \& Forder, 2019, Study 3; but see Zingora \& Graf, 2019, for evidence against attitude generalization), qualifying it as the main mediator of the STE.

\subsection{2 | Intergroup emotions}

Intergroup emotions, such as empathy and intergroup anxiety, have been found to be the key mediating processes of the intergroup contact-outgroup attitudes path (Brown \& Hewstone, 2005; Pettigrew \& Tropp, 2008). However, the role of intergroup emotions has only received scarce attention in STE research.

Evidence for the role of intergroup emotions was provided by Vezzali and Giovannini (2012). They found crosssectionally that Italian high-school students' positive contact with immigrants (primary outgroup) was indirectly associated with improved attitudes toward gay people and individuals with disability (secondary outgroups), via attitudes toward the primary outgroup, and via anxiety and perspective-taking toward secondary outgroups (for additional evidence of perspective-taking as a mediator of the STE, see Schulz \& Taylor, 2018; Vezzali \& Giovannini, 2011). Similarly, Turner and Feddes (2011) found that White undergraduates' intimacy of disclosure with an outgroup person was associated with lower anxiety toward a wide range of secondary outgroups and in turn with more positive outgroup attitudes toward these groups approximately 6 weeks later.

Giovannini and Vezzali (2011) investigated whether contact between Italian teachers and immigrant parents (primary outgroup) generalizes to reduced prejudice for immigrant children (secondary outgroup), in terms of supporting social policies favoring this group, desire for their school integration, and perceptions of them as an heterogeneous group. Results showed support for the STE, which was mediated by increased empathy toward the primary outgroup.

The range of emotions explaining the STE was expanded by Zezelj et al. (2020) to include outgroup trust. Using a probability sample of adolescents from five Balkan countries, the authors conducted a cross-sectional study, where various marginalized groups represented the primary outgroup (people with disability, Roma, ethnic groups, poor people) and gay people was the secondary outgroup. Results provided evidence for increased trust toward both the primary and secondary outgroup, and attitude generalization, as the underlying processes. 


\subsection{3 | Outgroup morality}

Morality, concerning perceptions of what is right and wrong, has been shown to impact on impression formation over important dimensions like sociability and competence (Brambilla, Biella, \& Freeman, 2018; Leach, Ellemers, \& Barreto, 2007), and to be an antecedent of outgroup attitudes (Brambilla \& Leach, 2014). Although traditionally separate, some studies integrating contact and morality research have shown that contact is associated with greater perceptions of the outgroup as moral, which is in turn associated with reduced prejudice (Brambilla, Hewstone, \& Colucci, 2013; Vezzali, Brambilla, Giovannini, \& Colucci, 2017).

Vezzali et al. (2019) conducted a cross-sectional study with majority (Italian) and minority (immigrant) highschool participants, testing morality and attitude generalization as concurrent processes. The primary outgroup was represented by the ethnic group (Italians for immigrants and immigrants for Italians); individuals with disability were the secondary outgroup. Results for the majority group revealed that the contact effects generalized to more positive attitudes and behavioral (contact) intentions toward the secondary outgroup via morality of the primary and secondary outgroups, and via attitudes toward the primary outgroup. Results for the minority group revealed mediation via morality of the secondary outgroup and attitudes toward the primary outgroup.

\subsubsection{Intergroup threat}

Intergroup threat is a strong predictor of prejudice (Riek, Mania, \& Gaertner, 2006) and an established mediator of the contact-reduced prejudice relationship (Aberson, 2019). Mähönen and Jasinskaja-Lahti (2016) conducted a study with a longitudinal two-wave design to examine the STE and mediation by intergroup threat. Participants were Russians living in Finland; Finnish people were the primary outgroup and other immigrants were the secondary outgroup. Intergroup threat toward the primary outgroup was operationalized with measures of perceived realistic and symbolic gains (conceptually, the opposite of threat), and with realistic and symbolic threat. Results showed mediation for perceived gains, but not for intergroup threat.

Further evidence for the mediating role of threat toward the primary outgroup was provided by Zingora and Graf (2019), who conducted a cross-sectional study to examine the STE from contact between Slovak and Roma people (primary outgroup) to attitudes and supportive voting behavior toward gay people (secondary outgroup). In this case, the STE emerged via threat toward the primary and, in turn, the secondary outgroup (a measure combining both realistic and symbolic dimensions of threat) rather than via attitude generalization; specifically, positive contact was associated with lower and negative contact (see section "Negative intergroup contact") with higher threat, which in turn mediated contact effects on outcome variables.

\section{2 | Mediators involving the ingroup}

\subsubsection{Deprovincialization: Ingroup identification and ingroup attitudes}

According to Pettigrew (1998), intergroup contact can widen individuals' horizons, demonstrating that social reality can be approached not solely based on social norms and traditions characterizing the ingroup, and that other groups and cultures can be characterized by equally acceptable social norms and customs. In other words, according to the deprovincialization hypothesis, a less provincial view of the ingroup would allow prejudice reduction. This hypothesis fits well with the premises of the STE. In fact, when individuals re-evaluate the ingroup, it is possible to improve attitudes toward several outgroups and not only toward one specific outgroup. 
A potential issue concerning the deprovincialization hypothesis is that Pettigrew $(, 1998)$ drafted it conceptually, but the actual operationalization of the ingroup reappraisal implied by deprovincialization is open to different approaches. Various scholars, for example, interpreted it in terms of ingroup identification: contact would lead to less identification with the ingroup and reduced identification would in turn lead to improved outgroup attitudes (Verkuyten, Thijs, \& Bekhuis, 2010). In the study by Pettigrew (2009), intergroup contact was indirectly associated with more positive attitudes toward secondary outgroups not only via improved outgroup attitudes toward the primary outgroup, but also via reduced identification with the national ingroup. However, ingroup identification was not a mediator of the STE in two studies conducted by Schmid et al. (2013), where instead outgroup attitudes and social identity complexity (in Study 2) emerged as significant underlying processes.

Adopting a different measure of ingroup identification, Tausch et al. (2010, Study 1), operationalized deprovincialization as private collective self-esteem (capturing self-esteem referred to both the self and the ingroup). Results revealed that contact predicted lower self-esteem and, in turn, reduced prejudice toward the secondary outgroup (note, however, that mediation by outgroup attitudes was stronger than mediation by collective selfesteem). Similarly, Brylka et al. (2016) used a measure of public collective self-esteem to test whether deprovincialization could account for the STE. The authors investigated whether contact between two minorities (Estonians and Russians) and the majority group (Finnish people) in Finland would be associated with more positive attitudes toward the other minority group, serving as the secondary outgroup (Estonians, for Russians; Russians, for Estonians). Results revealed that public collective self-esteem (together with attitudes toward the primary outgroup) mediated the STE for both groups. Note however that, in partial contrast with findings by Tausch et al. (2010, Study 1), the mediation effect was driven by the improvement and not the reduction in collective selfesteem. Findings for collective self-esteem were, in any case, not replicated in Tausch et al.'s (2010) longitudinal study (Study 4), where only outgroup attitudes and not private collective self-esteem emerged as a significant mediator.

Deprovincialization or ingroup reappraisal has also been operationalized as ingroup attitudes. The hypothesis in this case is that contact leads to a re-appraisal of the ingroup; by evaluating the ingroup less positively, attitudes toward the secondary outgroup are, in turn, improving. Tausch et al. (2010) tested ingroup attitudes as a form of deprovincialization in three of their four studies (Studies 2-4), but they found no supporting evidence for it. Similar findings were obtained in the two studies conducted by Schmid et al. (2013) and in one experimental study by Shook et al. (2016).

Overall, research regarding the role of ingroup identification and ingroup attitudes, as operationalizations of deprovincialization, is rather inconclusive, showing little evidence for deprovincialization as an underlying process characterizing the STE.

\subsubsection{Social identity complexity}

Schmid et al. (2013) identified social identity complexity as a further potential process underlying the STE. Social identity complexity is a construct originally proposed by Brewer and collaborators (Brewer \& Pierce, 2005; Roccas \& Brewer, 2002), referring to the appraisal of one's ingroup identities as more or less complex, in terms of how they are differentiated and inclusive. It is possible to distinguish two forms of social identity complexity. Overlap complexity concerns the extent to which one believes their ingroup identities overlap, with complexity increasing the more ingroup identities are perceived as distinct. Similarity complexity, instead, refers to whether the properties of ingroup categories (e.g., prototypes) are appraised as similar: the more individuals perceive dissimilarity among categories, the more they are characterized by similarity complexity.

Schmid et al. (2013) argued that intergroup contact may bring attention to the outgroup and to the fact that its members may form an outgroup on some categories, but also an ingroup on other categories, increasing the perceived complexity of ingroup categories (e.g., for a British woman, an Indian woman is an outgroup member in terms of the nationality category, 
but an ingroup in terms of the gender category). In turn, social identity complexity, drawing on the principles of multiple categorization (Crisp \& Hewstone, 2007), whereby simultaneous awareness of belonging to different groups reduces prejudice, should relate to more positive outgroup attitudes (Schmid, Hewstone, Tausch, Cairns, \& Hughes, 2009). Social identity complexity may also be relevant to the STE: to the extent that individuals perceive that their identities are complex and often shared, at least in part, with other individuals, prejudice toward a wide range of outgroups should be reduced.

This hypothesis was tested in two cross-sectional studies by Schmid et al. (2013). In the first study, participants were Germans, the primary outgroup was Turks, and the secondary outgroups were West-Europeans and Russians. In the second study, participants were Catholics and Protestants from Northern Ireland, the primary outgroup was the opposing religious group (Protestants for Catholics, and vice versa), and the secondary outgroups were racial minorities, gay people, people belonging to the travelling community. Results of Study 2 revealed mediation by both types of social identity complexity (overlap and similarity), although the indirect effects via attitude generalization were of greater magnitude. In contrast, Study 1 did not yield evidence for social identity complexity as a mediator.

Based on the above findings, although social identity complexity is theoretically a relevant factor that can explain the STE, current empirical evidence is inconclusive. Further research is necessary to explore this factor in more depth.

\section{3 | Mediators involving the self}

\subsection{1 | Personality and ideological variables}

Adding to research showing that personality is associated with intergroup contact (Sibley \& Duckitt, 2008; Turner, Dhont, Hewstone, Prestwich, \& Vonofakou, 2014), Vezzali, Turner et al. (2018) showed that this correlation is bidirectional. In other words, not only can personality influence the frequency and quality of contact, but contact can contribute to shape personality. We posit that changes in personality might also explain the STE. To the extent that a person becomes more open to experiences and agreeable as a function of contact (Vezzali, Turner et al., 2018), and that these factors are associated with improved outgroup attitudes (Sibley \& Duckitt, 2008), then prejudice toward a variety of groups (Akrami et al., 2011; Sibley \& Duckitt, 2008) (and not only toward the outgroup one has had contact with) may decline.

Empirical support for this hypothesis was provided by testing the role of SDO as a mediator of the STE. SDO can be conceptualized as a social-ideological, individual difference variable reflecting support for social hierarchies. Although SDO is shaped by multiple factors, personality is a strong determinant of it, which is why SDO largely qualifies as a personality factor (Sidanius \& Pratto, 1999). Evidence suggests that contact can change SDO, making individuals more oriented toward tackling intergroup inequalities (Dhont, Van Hiel, \& Hewstone, 2014). By developing an orientation against intergroup inequalities, individuals may as well display reduced prejudice toward a wide range of outgroups, therefore supporting the main idea underlying the STE.

Direct evidence for the role of SDO as a mediator of the STE was provided by Shook et al. (2016) in one rare study examining the STE with an experimental approach. Participants were first-year university students who had randomly been assigned to live with a same-race or another-race roommate. Results showed that participants assigned to live in rooms with another-race partner displayed less SDO, and in turn reduced prejudice toward a series of racial secondary outgroups 2-3 months after room assignments.

Additional evidence was provided by Vezzali, Di Bernardo, et al. (2018), who examined cross-sectionally the relationship between contact among Italian elementary schoolchildren and immigrants (with immigrants being the primary outgroup for Italians, and vice versa) and attitudes toward children with disability (secondary outgroup). Results revealed that among Italians contact was indirectly associated with reduced prejudice toward the secondary outgroup via a reduction in SDO, and in turn improved attitudes toward the primary outgroup. The results yielded support to both SDO and attitude generalization 
as mediating processes. The STE, however, did not emerge when considering immigrant children as participants (i.e., it only emerged when testing the majority group, but not the minority group), an effect likely due to the lower effectiveness of contact among minority groups (Tropp \& Pettigrew, 2005).

Taken together, we can state that personality can be a pertinent explanation for the STE, but additional empirical evidence is needed. A comprehensive integration of personality and STE literature can provide a fruitful avenue of research that can shed further light in factors that explain the STE.

In conclusion, research has provided evidence for the three types of mediators. However, while according to our tables scholars mostly focused on mediators concerning the outgroup (48 tests from 30 studies, 21 of which examined attitude generalization), they overlooked mediators concerning the ingroup (18 tests from 12 studies) and, especially, mediators involving the self (three tests from three studies). It is worth noting that in the three studies testing mediators involving the self, two focused on SDO. Therefore, although we hypothesize STE via personality (Figure 1), research has yet to provide evidence for such a relationship.

\section{6 | MODERATORS OF THE SECONDARY TRANSFER EFFECT}

Research has mainly explored mediators, rather than moderators of the STE. Therefore, research on moderators is rather scarce. Generally, we argue that moderators of the STE largely coincide with moderators of the effects of intergroup contact on the primary outgroup. Specifically, variables that strengthen or diminish the effects of contact on attitudes toward the outgroup are likely to have a cascade effect on attitudes toward the secondary outgroup. One such moderator is group status, with effects that sometimes differ between majority and minority groups. In line with the contact literature (Tropp \& Pettigrew, 2005), STE outcomes are generally larger among the majority group (Vezzali , Di bernardo et al., 2018, 2019; but see Tausch et al., 2010, Study 1). SDO was identified as a further moderator but interestingly, in contrast with findings that point to contact effects being generally stronger for individuals high in SDO (Hodson, Turner, \& Choma, 2017), the STE emerged for individuals low in SDO (Schmid et al., 2012). This finding requires some further examination as the scale used to assess SDO was a shorter version of the oft-used $\mathrm{SDO}_{6}$ scale.

Pettigrew (2009) hypothesized the existence of a similarity gradient, such that the STE might be more likely to occur when primary and secondary outgroups are similar rather than dissimilar. However, various studies found generalization for both similar and dissimilar outgroups (e.g., Pettigrew, 2009; Tausch et al., 2010; Vezzali et al., 2019), therefore providing modest evidence for a similarity gradient. The only test for similarity between primary and secondary outgroups that we are aware of has been conducted by Harwood et al. (2011), focusing on an indirect form of contact (see section "Indirect intergroup contact"), and using external raters to define secondary outgroups as similar or dissimilar compared to the primary outgroup. Results revealed that American students' (imagined) contact with illegal immigrants was associated with more positive attitudes toward a higher number of similar than dissimilar outgroups (but a formal test of moderation was missing). Note that defining whether outgroups are similar or dissimilar may be difficult (cf. Lolliot et al., 2013; Pettigrew, 2009) and highly subjective, complicating the investigation of this moderator.

Jasinskaja-Lahti et al. (2020) conducted an experimental study investigating a moderator specific to the STE (which should moderate the generalization from attitudes toward the primary outgroup to attitudes toward the secondary outgroup; see Figure 1), in addition to a further moderator of contact, that is initial prejudice. The authors focused on the role of moral credentials and specifically on the moral licensing effect (Monin \& Miller, 2001). This effect is based on the notion that acquiring moral credentials with a moral act might inhibit a subsequent moral act. Applied to the STE, the authors investigated whether performing a moral act toward the primary outgroup would block generalization to the secondary outgroup. Participants were Finnish people; immigrants with African origins were the primary outgroup and immigrants with Russian origins were the secondary outgroup, respectively (but primary and secondary outgroups were counterbalanced between 
participants, so that for half of the participants Russian immigrants were the primary outgroup and African immigrants were the secondary outgroup).

Participants in the experimental condition engaged in the acquisition of moral credentials, by hiring an individual belonging to the primary outgroup (who was the best candidate for the job in the scenario presented); participants selected an ingroup person (presented as the best candidate) in the control condition. Results revealed that the effects of contact on attitudes toward the secondary outgroup via attitudes toward the primary outgroup were blocked (i.e., the STE did not emerge) in the experimental condition and when participants displayed higher initial prejudice. Interestingly, although individuals generally benefit more from intergroup contact when they are highly prejudiced (Hodson et al., 2017), the results of this study show that, consistent with the aversive racism paradigm (Dovidio \& Gaertner, 2004), they do not show a generalized reduction in prejudice if they can avoid it (by "using" acquisition of moral credentials as an excuse).

The scarce research on moderators of the STE implies the imperative need for further examination of relevant moderating factors. It is in fact important to understand when and under which conditions the STE emerges, as this will allow more effective implementation of ways to enhance it.

\section{\begin{tabular}{l|l}
7 & INDIRECT INTERGROUP CONTACT
\end{tabular}}

Research over the past 20 years has provided evidence for the effectiveness of indirect contact methods, that is, contact which is not face-to-face, and that can be used when direct contact is not feasible or can complement direct contact methods (Turner, Hewstone, Voci, Paolini, \& Christ, 2007). The main types of indirect contact identified by research are imagined contact, that is, the mental simulation of a positive intergroup interaction (Crisp \& Turner, 2012); extended contact, that is, knowing that ingroup members have contact with outgroup members; and vicarious contact, referring to the observation of an intergroup encounter (Vezzali, Hewstone, Capozza, Giovannini, \& Wölfer, 2014; Wright, Aron, McLaughlin-Volpe, \& Ropp, 1997; Zhou, Page-Gould, Aron, Moyer, \& Hewstone, 2019).

Research on indirect contact and the STE is still in its infancy. As can be seen in the tables, only eight studies investigated the STE stemming from indirect contact. Of these, six (four on imagined contact and two on vicarious contact) have been conducted experimentally, and none longitudinally; of the two studies using cross-sectional data (both on extended contact), one used a combined measure that did not allow to distinguish extended from direct contact (Schmid et al., 2012). However, findings show that indirect contact, although its effects may be weaker than those of direct contact (Christ et al., 2010), can result in STE. Vezzali et al. (2019) found that extended contact led to STE both via attitude generalization and via perceived morality of primary and secondary outgroups among both majority and minority group members. With respect to vicarious contact, Joyce and Harwood (2014) showed that observing a positive (vs. negative or neutral) intergroup interaction generalized to more positive attitudes toward secondary outgroups by means of attitude generalization. Andrews (2018) tested the effects of observing a positive, a negative, or a neutral interaction between an ingroup poker player and a Russian (outgroup) player among New Zealand participants. Attitudes toward Chinese people-the secondary outgroup-were more positive in the positive versus the negative and neutral conditions (but no STE emerged for the secondary outgroups of Arabs or Americans).

Finally, four experimental studies showed that imagined contact can result in STE, also toward dissimilar outgroups (Harwood et al., 2011, via attitude generalization; Visintin et al., 2017), and in naturalistic contexts like in the workplace (De Carvalho-Freitas \& Stathi, 2017).

Given this evidence, we hypothesized in Figure 1 that indirect contact could exert its effects mainly via mediators concerning the outgroup or the ingroup (although research only provided evidence on mediators concerning the outgroup). Given the weaker effects of indirect compared to direct contact (Christ et al., 2010), it may not be sufficiently strong to impact 
on relatively stable constructs such as ideological and personality variables (although this is also a research direction worthy of investigation).

\section{NEGATIVE INTERGROUP CONTACT}

Negative contact is the focus of ample emerging contact literature (Graf \& Paolini, 2017). Research has shown that negative contact is typically associated with increased prejudice, and its effects are sometimes of greater magnitude than those of positive contact (Barlow et al., 2012; Paolini, Harwood, \& Rubin, 2010; Paolini \& McIntyre, 2019). Research is also emerging with respect to negative contact and the STE.

Research findings generally show the existence of the STE also in the case of negative contact, although research is scarce (nine studies, three of which on indirect contact, see Tables 1-3). The mediating processes seem to be the same as those identified for the STE of positive contact. Meleady and Forder (2019, Study 3) tested an "avoidance generalization effect," and found that negative contact was associated with lower intentions to engage in contact with the primary outgroup and, in turn, with the secondary outgroup (in some way, showing attitude generalization of negative contact). Brylka et al. (2016) found evidence for the STE also for negative contact, mediated by public collective self-esteem and attitudes toward the primary outgroup (as was the case of positive contact, but in the opposite direction). Lissitsa and Kushnirovich (2018) found that both positive and negative contact effects generalized to the secondary outgroup via attitudes toward the primary outgroup (but the indirect effect was greater for positive than for negative contact).

Zingora and Graf (2019) found that the STE emerged for negative contact, mediated by realistic and symbolic threat toward primary and secondary outgroup (but no evidence for attitude generalization emerged). In contrast, in the longitudinal study by Mähönen and Jasinskaja-Lahti (2016), the STE for negative contact did not emerge, neither via perceived gains nor via intergroup threat. Finally, Jasinskaja-Lahti et al. (2020) showed that the STE for negative contact emerged when individuals could not "use" the acquisition of moral credentials to prevent it or when moral credentials were acquired by low-prejudiced individuals.

\section{FUTURE DIRECTIONS}

We argue that our distinction of mediators in three categories can shed light on the potential of contact to foster different generalizations and stimulate new research. Such a distinction also allows to highlight that while there is ample research in terms of processes involving the outgroup, which are largely similar to mediators identified by classic contact research, we know little about processes involving the ingroup, and even less about processes involving the self. As such, more emphasis can be placed on identifying and testing relevant mechanisms in the effort to fully understand the STE.

As anticipated, one research direction worthy of exploration concerns the nature of prejudice toward the secondary outgroup(s). Surprisingly, literature on the STE has been detached from that on generalized prejudice, despite that the STE clearly speaks to it. Therefore, integrating these two perspectives can be fruitful both theoretically and empirically. For instance, researchers may identify different underlying processes predicting the different types of generalization. Drawing on our distinction, mediators involving the ingroup or the self would likely be good candidates in explaining changes concerning generalized prejudice. Also, changes in how the primary outgroup is appraised may produce generalization to members of that outgroup or similar outgroups, but they may be unlikely to produce attitude change toward dissimilar outgroups (since such changes are based on the characteristics of the outgroup encountered). In contrast, perceiving the ingroup as deprovincialized would allow to restructure own perceptions about the ingroup and how it should relate to other groups, rather independently from the outgroup under consideration; this process would therefore permit a reduction in generalized prejudice. Similarly, changes in the self (e.g., strength of personality traits) are unrelated to a defined outgroup category but 
would allow modifying the way one approaches other persons or groups in general; this way, attitude change would include a wide range of outgroups (cf. Vezzali \& Stathi, 2021, Chapter 6).

A related direction for future research concerns the potential of intergroup contact to achieve cognitive liberalization. Hodson et al. (2018) attribute this potential to the fact that contact can take many forms and impact on a wide range of psychological processes, allowing multifaceted effects. Amongst these are effects unrelated to intergroup interactions and outgroup attitudes, such as increases in flexibility, creativity, and problem-solving skills (Crisp \& Turner, 2011; Gocłowska \& Crisp, 2014), as well as unexpected outcomes apparently unrelated to intergroup relations, such as increased environmental concerns (Meleady, Crisp, Dhont, Hopthrow, \& Turner, 2020).

Our classification of mediators reflects the cognitive liberalization posited by Hodson, Meleady, and colleagues. Also in this case, mediators that can be especially relevant are those involving the ingroup and the self. In fact, changes related to the ingroup(s) reflect a new conceptualization of the society and of hierarchy structures, based on which the ingroup is just one of its components. This relates to abstract categorization and higher-order processes that facilitate the understanding of a complex society. Changes related to the self imply different ways of approaching issues and social relations, likely impacting much more than the single group one has had contact with on processes like flexibility and creativity. We argue that future research should better understand the different ways contact can act as a liberalizing agent, how this relates to the STE and consequently to generalized prejudice.

More generally, the question therefore is not whether the STE emerges more strongly when primary and secondary outgroups are similar or dissimilar, or which are the types of generalizations that can be achieved, but which are the specific processes driving each of these effects (cf. Vezzali \& Stathi, 2021, Chapter 6).

We also identify more clearly defined directions for future research, as implied by the different sections of this article. First, more research is needed on the STE of negative contact. As the line of research on negative contact is growing, a focus on the STE can be particularly fruitful. Second, research on indirect contact and the STE is only scarce and also requires further exploration. With respect to these points, it is worth investigating the combined effects of positive and negative contacts, as well as that of the different types of contact. For instance, ingroup and outgroup norms, tapping on mediators that we classified as regarding the ingroup or the outgroup, have been shown to be the primary mediators of extended and vicarious contacts (White et al., 2020). Again, based on the notion that indirect experiences produce weaker effects than direct experiences (Fazio, Powell, \& Herr, 1983), various authors theorized that the effects of indirect forms of contact can be lower than that of direct contact (Crisp \& Turner, 2012; Turner et al., 2007). Since we argued that mediators involving the self largely refer to personality or ideological variables likely resistant to change, they may be less affected by indirect forms of contact (see Figure 1).Third, it is important to identify mediators and moderators specific to the STE, rather than focusing solely on those identified in the contact literature. In other words, we should understand not only when and why contact reduces prejudice (we already have ample empirical evidence on this), but also when and why this effect will generalize beyond the specific outgroup(s) encountered. For instance, salience of shared characteristics between primary and secondary outgroups, or their inclusion in an overarching category (e.g., humanity), may facilitate the STE.

\section{\begin{tabular}{l|l}
10 & CONCLUSION
\end{tabular}}

Lolliot et al.'s (2013) review already provided evidence for the occurrence of the STE. It also identified key mediating processes, such as attitude generalization, deprovincialization via ingroup attitudes and identification, empathy, and moderating variables, such as SDO and similarity between primary and secondary outgroups. We believe that in the years following Lolliot et al.'s literature, the findings on the STE largely expanded. At the quantitative level, the existence of the STE has been largely confirmed, as has its potential to transfer to dissimilar outgroups. Methodological issues have been substantially overcome. New mediators have been uncovered, deprovincialization has been largely questioned as a mediating 
process (at least, in terms of how the variable has been operationalized), attitude generalization has been confirmed as the main driving process (probably reflecting the scholars' attention to studying it). Research has rather neglected the investigation of moderators, although new moderators emerged since Lolliot et al.'s review (notably, moral licensing as a moderator specific to the STE; Jasinskaja-Lahti et al., 2020).

We believe that the main improvements from Lolliot et al.'s (2013) review are at the conceptual level. First, with a wide range of mediators and empirical support for them, we were able to classify them in distinct categories that may drive future research. Second, paralleling the growth of studies of negative contact in the more general contact research, it is now clear that the STE also applies to negative contact, and its effects may counteract (or interact) with those of positive contact. Third, mirroring the growing amount of research on indirect contact, there are indications that the different indirect contact strategies may also drive the STE.

The aim of the present article was to review research on the STE related to different forms of contact (direct and indirect, positive and negative), identifying and categorizing the main underlying processes of the STE, especially in light of the development of future research. A quantitative analysis (i.e., a meta-analysis) focusing on establishing the effect size of the STE, the eventual role of publication bias, the relative impact of methodological issues (e.g., research design), was therefore beyond the scope of this review. However, we argue for the need of such quantitative analysis that will allow to better define the size of the STE as well as some of its defining conditions.

Research on the STE has progressed substantially in these few years, although it is still quite limited compared to the amount of research pertaining to the effects of intergroup contact on the primary outgroup. Our belief is that the STE is still an under-studied topic, but one that has a lot of potential. At the academic level, it can sensibly expand knowledge on strategies and mechanisms of prejudice reduction. Importantly, this can be done at an interdisciplinary level. As an example, various authors suggested that prejudice reduction interventions should occur early during the development, when attitudes are still malleable (Raabe \& Beelmann, 2011). The role of cognitive, social, and moral development should therefore be taken into account (Rutland \& Killen, 2015), calling for an integration between the fields of social, cognitive, and developmental psychology. This review can also inform policy considerations and interventions. Identifying effective strategies that promote generalized reductions in prejudice may tackle conflict which pervades diverse societies. With respect to this point, the examination of indirect contact strategies is especially relevant. The main benefit of indirect compared to direct contact is its greater ease of implementation (e.g., use in segregated contexts) and the possibility to reach a larger number of individuals (Vezzali \& Stathi, 2021, Chapter 6). In addition, to the extent that the broader benefits of contact (relating to cognitive liberalization) have yet to be identified, such strategies may do more than "simply" reduce prejudice, allowing for a more extensive improvement of the individuals and the society as a whole.

To the extent that researchers are interested in understanding how contact can lower social inequalities and lead to a positive approach to diversity and to greater social equality, understanding how prejudice toward a wide range of groups can be reduced is of primary importance.

\section{CONFLICT OF INTEREST}

The authors declare no conflict of interest.

\section{ORCID}

Loris Vezzali (D) https://orcid.org/0000-0001-7536-9994

Gian Antonio Di Dernardohttps://orcid.org/0000-0002-3922-5712

Veronica Margherita $\quad$ (iD) Coccohttps://orcid.org/0000-0002-1777-397X

Sofia Stathi (D) https://orcid.org/0000-0002-1218-5239

Dora Capozza 
Aberson, C. L. (2019). Indirect effects of threat on the contact-prejudice relationship: A meta-analysis. Social Psychology, 50, 105126. https://doi.org/10.1027/1864-9335/a000364

Akrami, N., Ekehammar, B., \& Bergh, R. (2011). Generalized prejudice: Common and specific components. Psychological Science, 22, 57-59. https://doi.org/10.1177/0956797610390384

Allport, G. W. (1954). The Nature of Prejudice. Cambridge, MA: Addison-Wesley.

Andrews, N. P., Yogeeswaran, K., Walker, M. J., \& Hewstone, M. (2018). Effect of valenced vicarious online contact on outgroup prejudice and perceived out-group variability: A study of online poker. Journal of Applied Social Psychology, 48, 571-581. https://doi.org/10.1111/jasp.12548

Barlow, F. K., Paolini, S., Pedersen, A., Hornsey, M. J., Radke, H. R. M., Harwood, J., ... Sibley, C. G. (2012). The contact caveat: Negative contact predicts increased prejudice more than positive contact predicts reduced prejudice. Personality and Social Psychology Bulletin, 38, 1629-1643. https://doi.org/10.1177/0146167212457953

Barr, J. J., \& Bracchitta, K. (2015). Attitudes toward individuals with disabilities: The effects of contact with different disability types. Current Psychology, 34, 223-238. https://doi.org/10.1007/s12144-014-9253-2

Berger, R., Benatov, J., Abu-Raiya, H., \& Tadmor, C. T. (2016). Reducing prejudice and promoting positive intergroup attitudes among elementary-school children in the context of the Israeli-Palestinian conflict. Journal of School Psychology, 57, 53-72. https://doi.org/10.1016/j.jsp.2016.04.003

Bergh, R., Akrami, N., Sidanius, J., \& Sibley, C. G. (2016). Is group membership necessary for understanding generalized prejudice? A re-evaluation of why prejudices are interrelated. Journal of Personality and Social Psychology, 111, 367-395. https://doi.org/10.1037/pspi0000064

Binder, J., Zagefka, H., Brown, R., Funke, F., Kessler, T., \& Mummendey, A. (2009). Does contact reduce prejudice or does prejudice reduce contact? A longitudinal test of the contact hypothesis among majority and minority groups in three European countries. Journal of Personality and Social Psychology, 96, 843-856. https://doi.org/10.1037/a0013470

Boin, J., Rupar, M., Graf, S., Neji, S., Spiegler, O., Swart, H., \& Voci, A. (2021). The generalization of intergroup contact effects: Emerging research, policy relevance, and future directions. Journal of Social Issues.

Bowman, N. A., \& Griffin, T. M. (2012). Secondary transfer effect of interracial contact: The moderating role of social status. Cultural Diversity and Ethnic Minority Psychology, 18, 35-44. https://doi.org/10.1037/a0026745

Brambilla, M., Biella, M., \& Freeman, J. B. (2018). The influence of visual context on the evaluation of facial trustworthiness. Journal of Experimental Social Psychology, 78, 34-42. https://doi.org/10.1016/j.jesp.2018.04.011

Brambilla, M., Hewstone, M., \& Colucci, F. P. (2013). Enhancing moral virtues: Increased perceived outgroup morality as a mediator of intergroup contact effects. Group Processes and Intergroup Relations, 16, 648-657. https://doi.org/ $10.1177 / 1368430212471737$

Brambilla, M., \& Leach, C. W. (2014). On the importance of being moral: The distinctive role of morality in social judgment. Social Cognition, 32, 397-408. https://doi.org/10.1521/soco.2014.32.4.397

Brewer, M. B., \& Pierce, K. P. (2005). Social identity complexity and outgroup tolerance. Personality and Social Psychology Bulletin, 31 , 428-437. https://doi.org/10.1177/0146167204271710

Brown, R., \& Hewstone, M. (2005). An integrative theory of intergroup contact. Advances in Experimental Social Psychology, 37, 255343. https://doi.org/10.1016/S0065-2601(05)37005-5

Brylka, A., Jasinskaja-Lahti, I., \& Mähönen, T. A. (2016). The majority influence on interminority attitudes: The secondary transfer effect of positive and negative contact. International Journal of Intercultural Relations, 50, 76-88. https://doi. org/10.1016/j.ijintrel.2015.12.007

Carvalho-Freitas, M. N. D., \& Stathi, S. (2017). Reducing workplace bias toward people with disabilities with the use of imagined contact. Journal of Applied Social Psychology, 47, 256-266. https://doi.org/10.10.1111/jasp.12435.

Christ, O., Hewstone, M., Tausch, N., Wagner, U., Voci, A., Hughes, J., \& Cairns, E. (2010). Direct contact as a moderator of extended contact effects: Cross-sectional and longitudinal impact on outgroup attitudes, behavioral intentions, and attitude certainty. Personality and Social Psychology Bulletin, 36, 1662-1674. https://doi.org/10.1177/ 0146167210386969

Clement, R., Gardner, R. C., \& Smythe, P.C (1977). Interethnic contact: Attitudinal consequences. Canadian Journal of Behavioral Science, 9, 205-215. https://doi.org/10.1037/h0081625.

Crisp, R. J., \& Hewstone, M. (2007). Multiple social categorization. Advances in Experimental Social Psychology, 39, $163-254$. https://doi.org/10.1016/S0065-2601(06)39004-1

Crisp, R. J., \& Turner, R. N. (2011). Cognitive adaptation to the experience of social and cultural diversity. Psychological Bulletin, 137, 242-266. https://doi.org/10.1037/a0021840

Crisp, R. J., \& Turner, R. N. (2012). The imagined contact hypothesis. Advances in Experimental Social Psychology, 46, 125-182. https://doi.org/10.1016/B978-0-12-394281-4.00003-9 
Dhont, K., Van Hiel, A., \& Hewstone, M. (2014). Changing the ideological roots of prejudice: Longitudinal effects of ethnic intergroup contact on social dominance orientation. Group Processes and Intergroup Relations, 17, 27-44. https://doi. org/10.1177/1368430213497064 
\&

Dovidio, J. F., $\quad$ Gaertner, S. L. (2004). Aversive racism. Advances in Experimental Social Psychology, 36, 1-51. https://doi.org/ 10.4135/9781412972017.n16

Eller, A., \& Abrams, D. (2004). Come together: Longitudinal comparisons of Pettigrew's reformulated intergroup contact model and the common ingroup identity model in Anglo-French and Mexican-American contexts. European Journal of Social Psychology, 34, 229-256. https://doi.org/10.1002/ejsp.194.

Fazio, R. H., Powell, M. C., \& Herr, P. M. (1983). Toward a process model of the attitude-behavior relation: Accessing one's attitude upon mere observation of the attitude object. Journal of Personality and Social Psychology, 44, 723-735. https://doi.org/10.1037/0022-3514.44.4.723

Giovannini, D., \& Vezzali, L. (2011). Contact with immigrant parents as a predictor of teachers' attitudes and acculturation orientations toward immigrant children. International Journal About Parents in Education, 5, 65-76.

Gocłowska, M. A., \& Crisp, R. J. (2014). How dual-identity processes foster creativity. Review of General Psychology, 18, $216-236$. https://doi.org/10.1037/gpr0000008

Graf, S., \& Paolini, S. (2017). Investigating positive and negative intergroup contact. In L. Vezzali \& S. Stathi (Eds.), Intergroup contact theory: Recent developments and future directions (pp. 92-113). Routledge.

Harwood, J., Paolini, S., Joyce, N., Rubin, M., \& Arroyo, A. (2011). Secondary transfer effects from imagined contact: Group similarity affects the generalization gradient. British Journal of Social Psychology, 50, 180-189. https://doi.org/10.1348/ 014466610X524263

Hindriks, P., Verkuyten, M., \& Coenders, M. (2014). Interminority attitudes: The roles of ethnic and national identification, contact, and multiculturalism. Social Psychology Quarterly, 77, 54-74. https://doi.org/10.1177/0190272513511469

Hodson, G., Crisp, R. J., Meleady, R., \& Earle, M. (2018). Intergroup contact as an agent of cognitive liberalization. Perspectives on Psychological Science, 13, 523-548. https://doi.org/10.1177/1745691617752324 Hodson, G., \&

Hewstone, M. (Eds.), (2013). Advances in intergroup contact. Psychology Press.

Hodson, G., Turner, R. N., \& Choma, B. L. (2017). Individual differences in intergroup contact propensity and prejudice reduction. In L. Vezzali, \& S. Stathi (Eds.), Intergroup contact theory: Recent developments and future directions (pp. 8-30). Routledge.

Jasinskaja-Lahti, I., Vezzali, L., Mona, R., Pagliaro, S., Giacomantonio, M., \& Pacilli, G. (2020). Conditional secondary transfer effect: The moderating role of prior moral credentials and prejudice. Group Processes and Intergroup Relations.

Joyce, N., \& Harwood, J. (2014). Improving intergroup attitudes through televised vicarious intergroup contact: Social cognitive processing of ingroup and outgroup information. Communication Research, 41, 627-643. https://doi.org/ $10.1177 / 0093650212447944$

Leach, C. W., Ellemers, N., \& Barreto, M. (2007). Group virtue: The importance of morality (vs. Competence and sociability) in the positive evaluation of in-groups. Journal of Personality and Social Psychology, 93, 234-249. https://doi.org/ 10.1037/00223514.93.2.234.

Levin, M. E., Luoma, J. B., Vilardaga, G., Lillis, J., Nobles, R., \& Hayes, S. C. (2016). Examining the role of psychological inflexibility, perspective taking, and empathic concern in generalized prejudice. Journal of Applied Social Psychology, 46, $180-191$. https://doi.org/10.1111/jasp.12355

LeVine, R. A., \& Campbell, D. T. (1972). Ethnocentrism: Theories of conflict, ethnic attitudes, and group behavior. Wiley.

Li, C., Li, D., Huang, Z., \& Chiu, C. (2016). Peace and war: Rewarding intergroup contacts make past intergroup aggression unforgivable. Peace and Conflict: Journal of Peace Psychology, 22, 166-167. https://doi.org/10.1037/pac0000140

Lissitsa, S., \& Kushnirovich, N. (2018). Secondary transfer effect of positive and negative online contact between groups involved in high-intensity conflict. International Journal of Intercultural Relations, 67, 71-80. https://doi.org/10.1016/j.

ijintrel.2018.10.001

Lolliot, S., Schmid, K., Hewstone, M., Al Ramiah, A., Tausch, N., \& Swart, H. (2013). Generalized effects of intergroup contact: The secondary transfer effect. In G. Hodson \& M. Hewstone (Eds.), Advances in intergroup contact (pp. 81-112). Psychology Press.

Mähönen, T. A., \& Jasinskaja-Lahti, I. (2016). Ramifications of positive and negative contact experiences among remigrants from Russia to Finland. Cultural Diversity and Ethnic Minority Psychology, 22, 247-255. https://doi.org/10.1037/ cdp0000059

Mark, N. P., \& Harris, D. R. (2012). Roommate's race and the racial composition of White college students' ego networks. Social Science Research, 41, 331-342. https://doi.org/10.1016/j.ssresearch.2011.11.012

Meeusen, C., Barlow, F. K., \& Sibley, C. G. (2017). Generalized and specific components of prejudice: The decomposition of intergroup context effects. European Journal of Social Psychology, 47, 443-456. https://doi.org/10.1002/ejsp.2252

Meleady, R., Crisp, R. J., Dhont, K., Hopthrow, T., \& Turner, R. N. (2020). Intergroup contact, social dominance, and environmental concern: A test of the cognitive-liberalization hypothesis. Journal of Personality and Social Psychology, 118, 1146-1164. https://doi.org/10.1037/pspi0000196 
\&

Meleady, R., Crisp, R. J., Hodson, G., \& Earle, M. (2019). On the generalization of intergroup contact: A taxonomy of transfer effects. Current Directions in Psychological Science, 28, 430-435. https://doi.org/10.1177/0963721419848682

Meleady, R., $\quad$ Forder, L. (2019). When contact goes wrong: Negative intergroup contact promotes generalized outgroup avoidance. Group Processes and Intergroup Relations, 22, 688-707. https://doi.org/10.1177/1368430218761568

Monin, B., \& Miller, D. T. (2001). Moral credentials and the expression of prejudice. Journal of Personality and Social Psychology, 81, 33-43. https://doi.org/10.1037/0022-3514.81.1.33

Paolini, S., Harwood, J., \& Rubin, M. (2010). Negative intergroup contact makes group memberships salient: Explaining why intergroup conflict endures. Personality and Social Psychology Bulletin, 36, 1723-1738. https://doi.org/10.1177/ 0146167210388667

Paolini, S., \& Mclntyre, K. (2019). Bad is stronger than good for stigmatized, but not admired outgroups: Meta-analytical tests of intergroup valence asymmetry in individual-to-group generalization experiments. Personality and Social Psychology Review, 23, 3-47. https://doi.org/10.1177/1088868317753504

Pettigrew, T. F. (1997). Generalized intergroup contact effects on prejudice. Personality and Social Psychology Bulletin, 23, $173-185$. https://doi.org/10.1177/0146167297232006

Pettigrew, T. F. (1998). Intergroup contact theory. Annual Review of Psychology, 49, 65-85. https://doi.org/10.1146/annurev. psych.49.1.65

Pettigrew, T. F. (2009). Secondary transfer effect of contact: Do intergroup contact effects spread to noncontacted outgroups? Social Psychology, 40, 55-65. https://doi.org/10.1027/1864-9335.40.2.55

Pettigrew, T. F., \& Tropp, L. R. (2006). A meta-analytic test of intergroup contact theory. Journal of Personality and Social Psychology, 90, 751-783. https://doi.org/10.1037/0022-3514.90.5.751

Pettigrew, T. F., \& Tropp, L. R. (2008). How does intergroup contact reduce prejudice? Meta-analytic tests of three mediators. European Journal of Social Psychology, 38, 922-934. https://doi.org/10.1002/ejsp.504

Raabe, T., \& Beelmann, A. (2011). Development of ethnic, racial, and national prejudice in childhood and adolescence: A multi-national meta-analysis of age differences. Child Development, 82, 1715-1737. https://doi.org/10.1111/j.14678624.2011.01668.x

Riek, B. M., Mania, E. W., \& Gaertner, S. L. (2006). Intergroup threat and outgroup attitudes: A meta-analytic review. Personality and Social Psychology Review, 10, 336-353. https://doi.org/10.1207/s15327957pspr1004_4

Roccas, S., \& Brewer, M. B. (2002). Social identity complexity. Personality and Social Psychology Review, 6, 88-106. https:// doi.org/10.1207/S15327957PSPR0602_01

Rutland, A., \& Killen, M. (2015). A developmental science approach to reducing prejudice and social exclusion: Intergroup processes, social-cognitive development, and moral reasoning. Social Issues and Policy Review, 9, 121-154. https://doi. org/10.1111/sipr.12012

Schmid, K., Hewstone, M., Küpper, B., Zick, A., \& Wagner, U. (2012). Secondary transfer effects of intergroup contact: A cross-national comparison in Europe. Social Psychology Quarterly, 75, 28-51. https://doi.org/10.1177/ 0190272511430235

Schmid, K., Hewstone, M., \& Tausch, N. (2013). Secondary transfer effects of intergroup contact via social identity complexity. British Journal of Social Psychology, 53, 443-462. https://doi.org/10.1111/bjso.12045

Schmid, K., Hewstone, M., Tausch, N., Cairns, E., \& Hughes, J. (2009). Social identity complexity: Intergroup contact, distinctiveness threat, and outgroup attitudes. Personality and Social Psychology Bulletin, 35, 1085-1098. https://doi. org/10.1177/0146167209337037

Schulz, M., \& Taylor, L. K. (2018). The processes underlying the quality of contact with the primary out-group and in-group importance on support for the Syrian resettlement in a post-accord context. Peace and Conflict: Journal of Peace Psychology, 24, 306-314.

Shook, N. J., Opkins, P. D., \& Koech, J. M. (2016). The effect of intergroup contact on secondary group attitudes and social dominance orientation. Group Processes and Intergroup Relations, 19, 328-342. https://doi.org/10.1177/ 1368430215572266

Sibley, C. G., \& Duckitt, J. (2008). Personality and prejudice: A meta-analysis and theoretical review. Personality and Social Psychology Review, 3, 248-279. https://doi.org/10.1177/1088868308319226

Sidanius, J., \& Pratto, F. (1999). Social dominance: An intergroup theory of social hierarchy and oppression. Cambridge University Press.

Sumner, W. G. (1906). Folkways. Ginn.

Tausch, N., Hewstone, M., Kenworthy, J. B., Psaltis, C., Schmid, K., PopanR, J., \& Hughes, J. (2010). Secondary transfer effects of intergroup contact: Alternative accounts and underlying processes. Journal of Personality and Social Psychology, 99, $282-302$. https://doi.org/10.1037/a0018553

Tropp, L. R., \& Pettigrew, T. F. (2005). Relationships between intergroup contact and prejudice among minority and majority status groups. Psychological Science, 16, 951-957. https://doi.org/10.1111/j.1467-9280.2005.01643.x 
$\&$

Turner, R. N., Dhont, K., Hewstone, M., Prestwich, A., \& Vonofakou, C. (2014). The role of personality factors in the reduction of intergroup anxiety and amelioration of outgroup attitudes via intergroup contact. European Journal of Personality, 28, 180-192. https://doi.org/10.1002/per.1927

Turner, R. N., Feddes, A. R. (2011). How intergroup friendship works: A longitudinal study of friendship effects on outgroup attitudes. European Journal of Social Psychology, 41, 914-923. https://doi.org/10.1002/ejsp.843

Turner, R. N., Hewstone, M., Voci, A., Paolini, S., \& Christ, O. (2007). Reducing prejudice via direct and extended cross-group friendship. European Review of Social Psychology, 18, 212-255. https://doi.org/10.1080/10463280701680297

Turner, R. N., Hodson, G., \& Dhont, K. (2020). The role of individual differences in understanding and enhancing intergroup contact. Personality and Social Psychology Compass, 14, e12533. https://doi.org/10.1111/spc3.12533

Van Laar, C., Levin, S., Sinclair, S., \& Sidanius, J. (2005). The effect of university roommate contact on ethnic attitudes and behavior. Journal of Experimental Social Psychology, 41, 329-345. https://doi.org/10.1016/j.jesp.2004.08.002

Verkuyten, M., Thijs, J., \& Bekhuis, H. (2010). Intergroup contact and ingroup reappraisal: Examining the deprovincialization thesis. Social Psychology Quarterly, 73, 398-416. https://doi.org/10.1177/0190272510389015

Vezzali, L., Brambilla, M., Giovannini, D., \& Colucci, F. P. (2017). Strengthening purity: Moral purity as a mediator of direct and extended contact on sexual prejudice. Journal of Homosexuality, 64, 716-730. https://doi.org/10.1080/00918369.2016.1196998

Vezzali, L., Di Bernardo, G. A., Birtel, M. D., Stathi, S., \& Brambilla, M. (2019). Outgroup morality perceptions mediate secondary transfer effects from direct and extended contact: Evidence from majority and minority members. Group Processes and Intergroup Relations. https://doi.org/10.1177/1368430219879223

Vezzali, L., Di Bernardo, G. A., Stathi, S., Cadamuro, A., Lasticova, B., \& Andraščiková, S. (2018). Secondary transfer effect among children: The role of social dominance orientation and outgroup attitudes. British Journal of Social Psychology, 57, 547-566. https://doi.org/10.1111/bjso.12248

Vezzali, L., \& Giovannini, D. (2011). Cross-group friendships, social dominance orientation and secondary transfer effect. Testing, Psychometrics, Methodology in Applied Psychology, 18, 181-194.

Vezzali, L., \& Giovannini, D. (2012). Secondary transfer effect of intergroup contact: The role of intergroup attitudes, intergroup anxiety and perspective-taking. Journal of Community and Applied Social Psychology, 22144, 125. https://doi. org/10.1002/casp.1103

Vezzali, L., Hewstone, M., Capozza, D., Giovannini, D., \& Wölfer, R. (2014). Improving intergroup relations with extended and vicarious forms of indirect contact. European Review of Social Psychology, 25, 314-389. https://doi.org/10.1080/ 10463283.2014.982948

Vezzali, L., \& Stathi, S. (2021). Using intergroup contact to fight prejudice and negative attitudes: Psychological perspectives. European Monographs in Social Psychology Series. Routledge.

Vezzali, L., Turner, R., Capozza, D., \& Trifiletti, E. (2018). Does intergroup contact predict personality? A longitudinal study on the bidirectional relationship between intergroup contact and personality traits. European Journal of Social Psychology. https://doi.org/10.1002/ejsp.2313

Visintin, E. P., Birtel, M. D., \& Crisp, R. J. (2017). The role of multicultural and colorblind ideologies and typicality in imagined contact interventions. International Journal of Intercultural Relations, 59, 1-8. https://doi.org/10.1016/j. ijintrel.2017.04.010

Weigert, K. M. (1976). Intergroup contact and attitudes about a third group: A survey of Black soldiers' perceptions. International Journal of Group Tensions, 6, 110-124.

White, F. A., Borinca, I., Vezzali, L., Reynolds, K. J., Blomster Lyshol, J. K., Verrelli, S., \& Falomir-Pichastor, J. M. (2020). Beyond direct contact: The theoretical and societal relevance of indirect contact for improving intergroup relations. Journal of Social Issues. https://doi.org/10.1111/josi.12400

Wilson, T. C. (1996). Prejudice reduction or self-selection? A test of the contact hypothesis. Sociological Spectrum, $16,43-60$.

Wright, S. C., Aron, A., McLaughlin-Volpe, T., \& Ropp, S. A. (1997). The extended contact effect: Knowledge of cross-group friendships and prejudice. Journal of Personality and Social Psychology, 73, 73-90. https://doi.org/10.1037/00223514.73.1.73

Zezelj, I. L., Milosevic-Dordevic, J., Van Niekerk, J., \& Pavlovic, Z. (2020). How to address the caveat of avoiding direct contact: Reducing prejudice towards gay and lesbian people in five Balkan countries. Journal of Social Psychology, 160, $190-203$. https://doi.org/10.1080/00224545.2019.1611531

Zhou, S., Page-Gould, E., Aron, A., Moyer, A., \& Hewstone, M. (2019). The extended contact hypothesis: A meta-analysis on 20 years of research. Personality and Social Psychology Review, 23, 132-160. https://doi.org/10.1177/ 1088868318762647

Zingora, T., \& Graf, S. (2019). Marry who you love: Intergroup contact with gay people and another stigmatized minority is related to voting on the restriction of gay rights through threat. Journal of Applied Social Psychology, 49, 784-703.

https://doi.org/10.1111/jasp.12627 


\section{AUTHOR BIOGRAPHIES}

Loris Vezzali is full professor of social psychology at the University of Modena and Reggio Emilia. His research mainly focuses on intergroup contact and the promotion of more positive intergroup relations.

Gian Antonio Di Bernardo is assistant professor of social psychology at the University of Modena and Reggio Emilia. His research interests mainly concern prejudice reduction, social change, humanity attributions in intergroup processes.

Veronica Margherita Cocco is a PhD student in social psychology. Her research focuses on collective action, intergroup bullying, and strategies aimed to reduce prejudice.

Sofia Stathi is Associate Professor of Social Psychology and Leader of the Centre for Inequalities at the University of Greenwich. Her research focuses on intergroup relations, with emphasis on exploring majority and minority group perspectives.

Dora Capozza is Emeritus Professor at the University of Padova (School of Psychology). She edited two books on social identity processes (with Rupert Brown). She is fellow of the American Psychological Society (APS). Her research concerns outgroup dehumanization, prejudice and dehumanization reduction, racial and ethnical disparities in medical contexts.

How to cite this article: Vezzali L, Di Bernardo GA, Cocco VM, Stathi S, Capozza D. Reducing prejudice in the society at large: A review of the secondary transfer effect and directions for future research. Soc Personal Psychol Compass. 2021;e12583. https://doi.org/10.1111/spc3.12583 